\title{
LAS ESPECIES DE SALVIA (LAMIACEAE) PARA ARGENTINA
}

\author{
Nataly O'Leary \& Pablo Moroni
}

Instituto de Botánica Darwinion (ANCEFN-CONICET), Labardén 200, Casilla de Correo 22, B1642HYD San Isidro, Buenos Aires, Argentina; noleary@darwin.edu.ar (autor corresponsal).

\begin{abstract}
O'Leary, N. \& P. Moroni. 2016. The species of Salvia (Lamiaceae) from Argentina. Darwiniana, nueva serie 4(1): 91-131.

Salvia is the biggest genus from Lamiceae, with almost 900 species. In Argentina it is represented by 23 taxa (20 species, one subspecies, and two varieties), four of these are adventive taxa, the rest are native, and one of these is endemic. Species are distributed predominantly in the north region of the territory, reaching the provinces of La Pampa and Mendoza as the southern limit of its distribution. Each of the 23 Salvia taxa present in Argentina is described and illustrated, and a key for their identification is presented. Three new synonyms are proposed, Salvia borjensis new synonym of Salvia nervosa, Salvia durifolia new synonym of Salvia ovalifolia var. ovalifolia and Salvia alba new synonym of Salvia personata, and ten lectotypes are designated for: Salvia approximata, S. arenaria, S. ovalifolia var. villosa, S. pallida, S. procurrens, S. reflexa, S. serrata, S. stachydifolia, S. uliginosa, and Salvia sect. Pycnosphace.
\end{abstract}

Keywords. Lamiaceae; lectotypifications; new synonyms; Salvia; taxonomy.

Resumen. O’Leary, N. \& P. Moroni. 2016. Las especies de Salvia (Lamiaceae) para Argentina. Darwiniana, nueva serie 4(1): 91-131.

Salvia es el género más grande de la familia Lamiaceae, con ca. 900 espcies. En Argentina está representado por 23 taxones (20 especies, una subespecie y dos variedades), cuatro de estos taxones son adventicios, el resto nativos y uno de ellos es endémico. Las especies se distribuyen principalmente en el norte del territorio, llegando a las provincias de La Pampa y Mendoza como límite sur de su distribución. Cada uno de los 23 taxones de Salvia presentes en Argentina es descripto e ilustrado y se presenta una clave para su identificación. Se proponen tres nuevos sinónimos, Salvia borjensis nuevo sinónimo de Salvia nervosa, Salvia durifolia nuevo sinónimo de Salvia ovalifolia var. ovalifolia y Salvia alba nuevo sinónimo de Salvia personata, y se designan diez lectotipos para: Salvia approximata, S. arenaria, S. ovalifolia var. villosa, S. pallida, S. procurrens, S. reflexa, S. serrata, S. stachydifolia, S. uliginosa y Salvia sect. Pycnosphace.

Palabras clave. Lamiaceae; lectotipificaciones; nuevos sinónimos; Salvia; taxonomía.

\section{INTRODUCCIÓN}

Salvia L. es el género más grande de la familia Lamiaceae, con ca. 900 especies (Harley et al., 2004). Se distribuye por todo el mun- do; el este y centro de Asia, la región mediterránea, y América del Sur y Central son los tres grandes centros de diversidad específica (Walker et al., 2004).

Las especies de Salvia son hierbas, sufrútices 
o arbustos, frecuentemente aromáticos. Las inflorescencias son pseudoracimos compuestos por verticilastros; el número de flores por verticilastro, así como el grado de densidad de los pseudoracimos, son caracteres importantes a nivel especie. Las flores son perfectas, zigomorfas, la longitud de la corola, del mismo modo que el color de la misma, también constituyen caracteres relevantes para diferenciar especies. La característica que permite distinguir el género Salvia es el aborto del par posterior de estambres y la concomitante presencia de sólo dos estambres con elongación del tejido conectivo que separa las tecas. Esta elongación del conectivo está asociada a un mecanismo de polinización exclusivo, en el cual el polinizador empuja la teca posterior mientras accede al néctar en la base del tubo de la corola, causando que la teca anterior deposite polen sobre el polinizador a través de un mecanismo de palanca (Sprengel, 1793; Himmelbaur \& Stibal, 1933-1935; Claßen-Bockhoff et al., 2003, 2004).

Recientes estudios filogenéticos en Salvia (Walker et al., 2004; Walker \& Sytsma, 2007), evidencian que el género no es monofilético y que este mecanismo de polinización asociado a la morfología estaminal habría surgido tres veces independientemente en el género. La clasificación propuesta por Epling $(1937,1939)$ sería artificial, basada en características morfológicas sin establecer relaciones filogenéticas.

La mayoría de las especies de Salvia se agrupan en el subgénero Calosphace (Benth.) Epling, taxón americano y monofilético (Walker et al., 2004). En la revisión de Salvia subg. Calosphace, Epling (1939) menciona ca. 500 especies y las divide en 91 secciones. Todas las especies de Salvia presentes en Argentina, tanto nativas como adventicias, pertenecen a este subgénero, excepto $S$. verbenaca L. que es orginaria de Europa y pertenece a la sect. Plethiosphace Bentham.

En Argentina, Salvia ha sido tratado de manera parcial en las floras regionales de Entre Ríos (Crespo, 1979) y Jujuy (Pontiroli, 1993). Epling (1937), en su trabajo de las labiadas de América del Sur, reconoce 18 especies para Argentina. Recientemente, Zuloaga et al. (2008), en un catálogo para Argentina, menciona 26 especies y dos variedades de Salvia.

Hasta el momento no existe una revisión ta- xonómica completa de Salvia para Argentina. El presente estudio provee una descripción completa de cada taxón de Salvia que crece en Argentina, junto con una clave para la identificación, ilustraciones, además de notas sobre nuevos sinónimos y tipificaciones.

\section{MATERIALES Y MÉTODOS}

Se han estudiado los ejemplares tipo y demás ejemplares de los herbarios BA, BAB, CTES, LIL y SI (Thiers, 2016). A continuación de las siglas del herbario se muestra el número de código de barras, o se indica el número del herbario precedido por un guión y en itálicas si no posee codigo de barras. Los materiales tipo fueron vistos en JSTOR (http:// plants.jstor.org/) o en las páginas Web de los herbarios (Ginebra: http://www.villege.ch/musinfo/bd/ cjb/chg/index.php?lang=fr). En todos los casos la elección del material designado como lectotipo se justifica por tratarse del material original más completo y representativo de la especie en cuestión.

En el material examinado sólo se mencionan ejemplares argentinos, y la descripción del género Salvia se basa en ese material. En el Apéndice 1 se brinda la lista de las especies y taxones infraespecíficos de Salvia aceptados para Argentina. En el Apéndice 2 se aporta un índice de colectores.

\section{TRATAMIENTO TAXONÓMICO}

Salvia L., Sp. Pl. 1: 23. 1753. ESPECIE TIPO: Salvia officinalis L. (designado por N. L. Britton \& A. Brown, Ill. Fl. N. U.S. (Britton \& Brown), ed. 2, 3: 129. 1913).

Arischrada Pobed., Novosti Sist. Vyssh. Rast. 9: 247. 1972, nom. nov. Schraderia Heist. ex Medik. 1791, nom. rej., non Schradera Vahl 1796, nom. cons. ESPECIE TIPO: no designada.

Audibertia Benth., Edwards's Bot. Reg. 15: sub t. 1282. 1829. ESPECIE TIPO: Audibertia pusilla Benth.

Kiosmina Raf., Fl. Tellur. 3: 92. 1836[1837]. ESPECIE TIPO: Kiosmina hispanica (L.) Raf. (= Salvia hispanica L.).

Polakia Stapf, Denkschr. Kaiserl. Akad. Wiss., Wien Math.-Naturwiss. Kl. 50(2): 43. 1885. ESPECIE TIPO: Polakia paradoxa Stapf. 
Pycnosphace (Benth.) Rydb., F1. Rocky Mts.: 1066. 1917. Salvia sect. Pycnosphace Benth., Labiat. Gen. Spec.: 206, 302. 1833. ESPECIE TIPO: Salvia columbariae Benth. (lectotipo aquí designado).

Ramona Greene, Pittonia 2(12): 301-302. 1892. ESPECIE TIPO: Ramona polystachya (Benth.) Greene (=Audibertia polystachya Benth.).

Salviastrum Scheele, Linnaea 22(5): 584-586. 1849, nom. illeg., non Heist. ex Fabr. 1759. ESPECIE TIPO: Salviastrum texanum Scheele.

Hierbas anuales o perennes o sufrútices o arbustos, muchas veces con raíces tuberosas, frecuentemente aromáticos, usualmente con pubescencia abundante sobre los tallos, pelos fasciculados o simples o glandulares sésiles o pedicelados. Hojas opuestas, simples, pecioladas o sésiles, frecuentemente pubescentes como en los tallos. Inflorescencias terminales y/o axilares, frecuentemente en pseudoracimos, formada por verticilastros distantes o aglomerados con 2-6(-20) flores. Brácteas florales decusadas, inconspicuas o grandes y algunas veces coloreadas, subyacentes o cubriendo los verticilastros en yema, caducas o persistentes. Flores perfectas, zigomorfas; bractéolas presentes o ausentes. Cáliz florífero bilabiado, tubo campanulado, labio superior entero o 3(4)-dentado, 3-8-nervado, labio inferior 2-dentado; cáliz fructífero frecuentemente acrescente. Corola marcadamente bilabiada, blanca o color celeste, azul, violeta, lila, rojo, anaranjado; tubo algunas veces giboso, labio superior más breve, entero o emarginado, labio inferior frecuentemente con un lóbulo central más ancho. Estambres fértiles 2, el par superior vestigial o ausente, el par inferior incluso o exerto; filamentos generalmente cortos; tecas generalmente una, conectivo alargado, frecuentemente mas largo que el filamento, generalmente articulado en el punto de unión al filamento, algunas veces dentado, los brazos superiores (polinatorio) ascendiendo por debajo del labio superior de la corola, algunas veces recurvado, sosteniendo las tecas fértiles, los brazos inferiores (vecciario) sosteniendo tecas reducidas, o reemplazados por callos aplanados, estos algunas veces connatos. Disco nectarífero 4-lobado. Ovario 4-lobado; estigma con dos ramas estigmáticas desiguales. Frutos en clusas, generalmente 4, trígonas, ovoides o elipsoidales, mucilaginosas o no, generalmente albuminosas, la cicatriz de abscisión pequeña.

Distribución y hábitat. Salvia posee ca. 900 especies de distribución cosmopolita, abundante en regiones montano tropicales. En Argentina crecen 23 taxones ( 20 especies, una subespecie y dos variedades), de los cuales 19 son nativos y cuatro adventicios. Salvia calolophos Epling es la única especie endémica de la Argentina. Las especies de Salvia crecen en suelos ricos, húmedos, o a veces también en suelos rocosos y algo arenosos, entre los 1000-3500 m s.m.

Observaciones. Bentham (1833: 206) menciona dos especies bajo Salvia sect. Pycnosphace (Benth.) Rydb., se elige una de ellas como lectotipo de la sección, optando por la única de éstas que Bentham refiere haber visto personalmente.

\section{Clave para diferenciar las especies y subespecies de Salvia en Argentina}

1. Corola de $35-50 \mathrm{~mm}$ S. guaranitica

1. Corola menor de $35 \mathrm{~mm}$

2(1). Brácteas florales persistentes, de 15-25 mm, color violeta, amplexicaules S. atrocyanea

2. Brácteas florales caducas o persistentes, de $2-15 \mathrm{~mm}$, generalmente verdes, no amplexicuales ........................... 3

3(2). Corola color rojo, anaranjado o rosado; de 20-35 mm ......................................................................... 4

3. Corola color azul o celeste, violeta, lila o blanca; de $6-15(-20) \mathrm{mm}$............................................................ 8

4(3). Hojas menores a $5 \mathrm{~cm}$; verticilastros 2-4-floros, excepcionalmente 6-floros en algún nudo ........ S. microphylla

4. Hojas generalmente mayores a $4 \mathrm{~cm}$; verticilastros multifloros ( 3 o más de 3 flores) ..... 5

5(4). Cáliz de 20-22 mm, color rojizo ................................................................................................ S. splendens

5. Cáliz de 6-15 mm, color verde, si rojizo, sólo en la madurez 
6(5). Plantas subglabras; corola de 20-22 $\mathrm{mm}$

S. subrotunda

6. Plantas pubescentes; corola de $25-32 \mathrm{~mm}$

7(6). Plantas pringosas con pubescencia glandular densa en tallos; hojas con pecíolo de 5-10 cm, lámina de 5-15 cm; cáliz de $10-15 \mathrm{~mm}$ S. exserta

7. Plantas no pringosas con pubescencia glandular breve y pelos largos hasta de 3-4 mm entremezclados; hojas con pecíolo de 1-2 cm, lámina hasta de 7,5 cm; cáliz de 8-9 $\mathrm{mm}$ S. coccinea

8(3). Hojas sésiles, subsésiles o con pecíolo hasta de $5 \mathrm{~mm}$ 9

8. Hojas pecioladas, con pecíolo mayor a $5 \mathrm{~mm}$ 11

9(8). Hojas con lámina ovado-ancha, igual o hasta 2 veces más largas que anchas, ápice agudo u obtuso, subsésiles o sésiles, base no amplexicaule S. ovalifolia

9. Hojas con lámina ovado-angosta o sublinear, aproximadamente 3 o más veces más largas que anchas, ápice agudo, sésiles, base amplexicaule 10 10(9). Hojas hasta de $1 \mathrm{~cm}$ lat., base connada S. rosmarinoides

10. Hojas de 1-2 cm lat., base no connada S. nervosa

11(8). Plantas con pelos fasciculados en partes vegetativas y piezas florales ................................................... 12

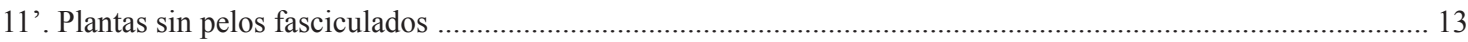

12(11). Cáliz de aspecto lanoso, con pelos fasciculados densos, breves, sin pelos uniseriados ni glandulares; cáliz joven con nervios poco visibles

S. calolophos

12. Cáliz con pubescencia variable, pelos uniseriados, con algunos pelos fasciculados largos, nunca breves y densos, con pelos glandulares pedicelados; cáliz joven con nervios visibles S. cuspidata subp. gilliesii 13(11). Verticilastros 10-20-floros, reunidos en pseudoracimos terminales densos; hojas y piezas florales con glándulas oleíferas

S. uliginosa

13. Verticilastros 3-12-floros, reunidos en pseudoracimos terminales laxos; hojas y piezas florales sin glándulas oleíferas 14

14(13). Caliz con el labio superior de ápice 3-dentado, diente medio menor S. verbenaca

14. Cáliz con el labio superior de ápice entero, emarginado o ligeramente 3-mucronado 15

15(14). Láminas con la base cordada 16

15. Láminas con la base aguda, redondeada o truncada 17

16(15). Plantas procumbentes, hojas con lámina ovada a suborbicular, ápice redondeado S. procurrens

16. Plantas erectas, hojas con lámina ovada a triangular, ápice agudo S. cardiophylla

17(15). Cáliz con el labio superior 3-nervado

S. personata

17. Cáliz con el labio superior 5-nervado 18

18(17). Hojas con lámina elíptico-angosta, hasta de $1 \mathrm{~cm}$ lat., base aguda, ápice obtuso; verticilastros de 2-4 flores S. reflexa

18. Hojas con lámina ovada, mayores a $1 \mathrm{~cm}$ lat., base redondeada o truncada, ápice agudo o acuminado; verticilastros de 3-12 flores

19(18). Tallos y cáliz con pelos glandulares conspicuos; verticilastros de 3-6 flores

S. rypara

19. Tallos y cáliz nunca con pubescencia glandular o si glandular no conspicua; verticilastros de 6-12-flores ........ 20

20(19). Brácteas florales persistentes en antesis; verticilastros florales espaciados 2-3 cm entre sí a la madurez; pseudoracimos laxos

S. pallida

20. Brácteas florales caducas en antesis; verticilastros florales espaciados 0,5-1 cm entre sí a la madurez; pseudoracimos densos S. stachydifolia

Salvia atrocyanea Epling, Repert. Spec. Nov Regni Veg. Beih. 85: 98. 1936. TIPO: Bolivia, Tarija, Narvais, between Tarija and Gran Chaco, 2000-2500 m, R. E. Fries 1282 (holotipo S-R-9018!). Fig. 1.
Salvia meyeri Legname, Lilloa 31: 245. 1962. TIPO: Argentina, sine loc., II-1960, T. Meyer 20505 (lectotipo LIL 001396! designado por O'Leary \& Moroni, Novon 24: 377. 2016; isolectotipos LIL 001397!, LIL 001398!, LIL 001399!). 


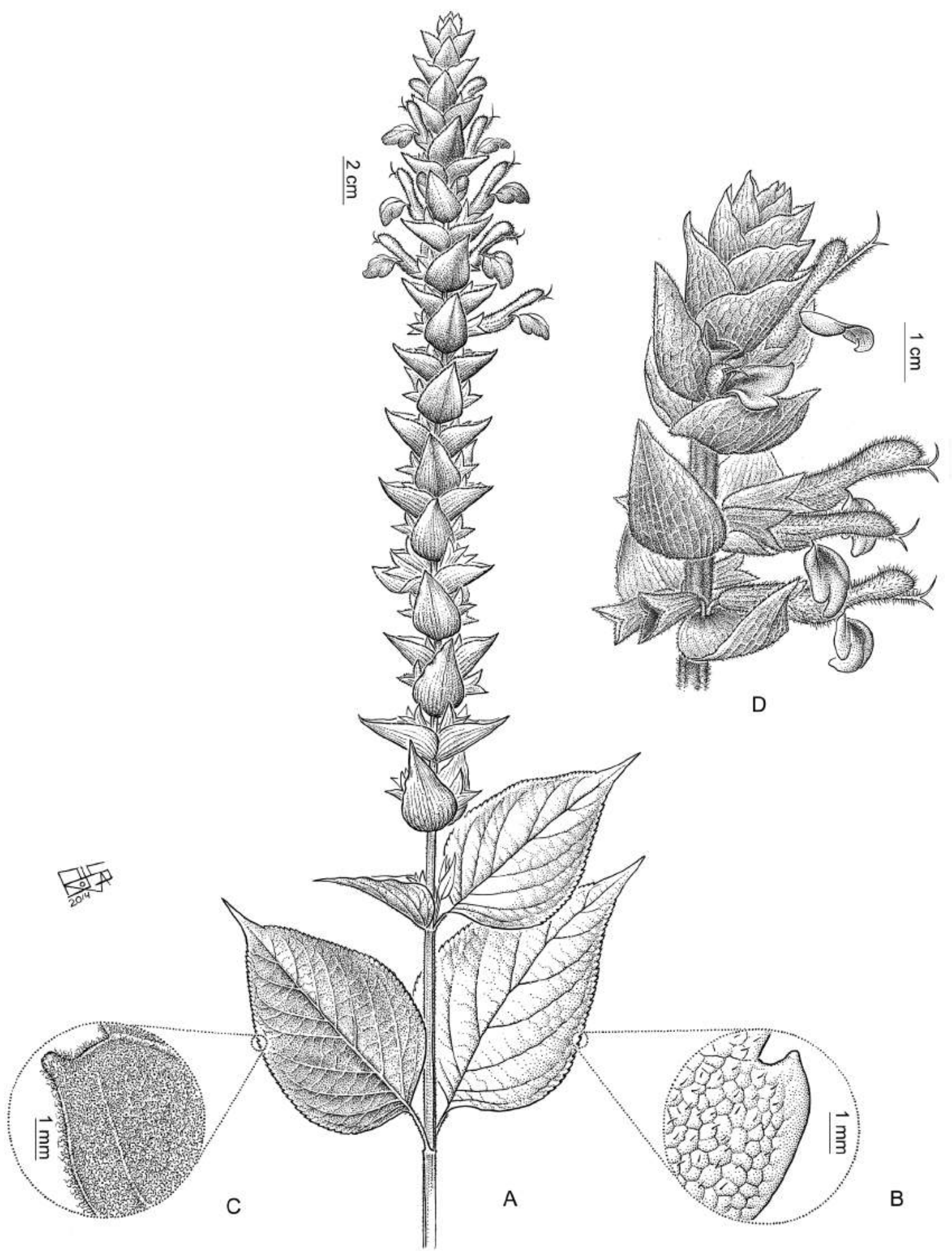

Fig. 1. Salvia atrocyanea. A, aspecto general. B, detalle de la pubescencia de hoja, cara adaxial. C, detalle de la pubescencia de hoja, cara abaxial. D, detalle de porción apical de inflorescencia. De Guaglianone 1858, SI. 

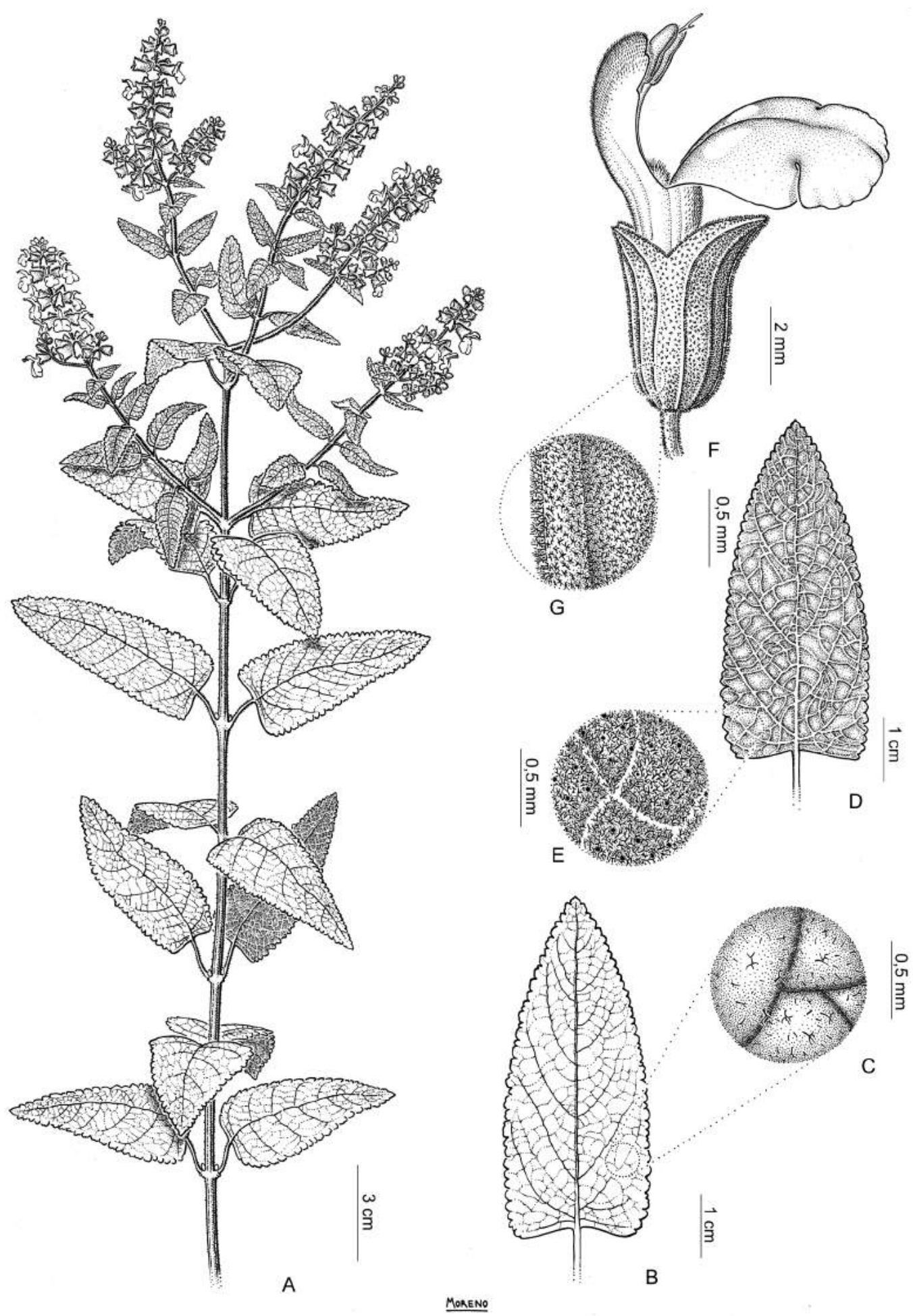

Fig. 2. Salvia calolophos. A, aspecto general. B, hoja, cara adaxial. C, detalle de pubescencia de hoja, cara adaxial. $\mathbf{D}$, hoja, cara abaxial. E, detalle de pubescencia de hoja, cara abaxial. F, flor. G, detalle de pubescencia del cáliz. De Hunziker 12589, SI. 
Sufrútice de 150-300 cm de alto, tallos cuadrangulares, leñosos hacia la base. Hojas con pecíolo de 1,5-2,5 cm, lámina de 5-16 × 3-9 cm, ovada u ovado-elíptica, ápice agudo, base truncada, margen aserrado, pubescencia escasa a densa. Flores pediceladas, pedicelo de 3-6 $\mathrm{mm}$, agrupadas en verticilastros de 6-10 flores, reunidos en pseudoracimos terminales densos de 5-30 cm. Brácteas florales persistentes en antesis y fruto, de 15-25 mm, ovadas, acuminadas, amplexicaules, de color violeta; cáliz de 12-18 $\mathrm{mm}$, labio superior entero, 5-8-nervado, el inferior 2-dentado, pubescencia escasa. Corola color azul, violeta, de $30-40 \mathrm{~mm}$, tubo de $15 \mathrm{~mm}$, labio superior de mayor tamaño que el labio inferior. Estambres inclusos. Estilo ligeramente exerto, de $11 \mathrm{~mm}$. Clusas de $3 \mathrm{~mm}$, elipsoides, ocráceas, lisas.

Distribución. Salvia atrocyanea es nativa de América del Sur, presente en Bolivia y en el noroeste de Argentina.

\section{Material representativo examinado}

ARGENTINA. Jujuy. Depto. Valle Grande, de San Fransisco a Alto de Calilegua, 21-II-2008, Zuloaga 10336 (SI). Salta. Depto. Santa Victoria, entre 3-4 km pasando canto del Monte, rumbo Lipeo, 11-III-2002, Negritto 492 (SI). Tucumán. Depto. Burruyacú, $5 \mathrm{~km}$ al N de Río Nío, camino a Sierra de Medina, 15-XII-2008, Slanis 31 12-2008 (SI).

Salvia calolophos Epling, Repert. Spec. Nov Regni Veg. Beih 85: 57. 1935. TIPO: Argentina, Salta, Campo Quijano, propre Rosario de Lerma, 1500 m, 16-I-1929, S. Venturi 8069 (holotipo US 0121426!; isotipos GH 0001817!, SI 002119!, US 01013739!). Fig. 2.

Sufrútice ramoso, hasta de $200 \mathrm{~cm}$ de alto, tallos ascendentes, pubescencia con pelos fasciculados. Hojas con pecíolo de 1-2 cm, lámina de 3-12 × 1,5$4 \mathrm{~cm}$, ovada, ápice agudo, base truncada o cordada, margen crenado, pubescenia abaxial densa, canescente a tomentosa, haz glabro a ralo. Flores brevemente pediceladas, pedicelo de 1-2 mm, agrupadas en verticilastros de 6-12 flores, reunidos en pseudoracimos terminales laxos o densos, de 8-15 $\mathrm{cm}$. Brácteas florales caducas, de 4-6 mm, ovadas, acuminadas, no amplexicaules, color verde; cáliz de 5-6 mm, acrescente, labio superior entero, ápice mucronado, 5-7-nervado, labio inferior 2-dentado, pubescencia lanosa densa de pelos fasciculados en la cara externa, nervios poco visibles por la pubescencia. Corola color azul o violeta, de $12-15 \mathrm{~mm}$, tubo de $6 \mathrm{~mm}$, glabro, giboso en la mitad dorsal, con dos papilas en la parte inferior de la cara interna, labio superior de 4-5 mm, cóncavo, emarginado, labio inferior de 6-8 mm. Estambres inclusos. Estilo exerto, de $10 \mathrm{~mm}$. Clusas de 2,5-3 mm, elipsoides, ocráceas, algo deprimidas, lisas.

Distribución. Salvia calolophos es endémica de Argentina, se la encuentra en suelos rocosos del noroeste y centro del territorio.

\section{Material representativo examinado}

ARGENTINA. Catamarca. Depto. Andalgalá, cuesta de la Chilca, Hunziker 12441 (SI). Córdoba. Depto. Ascochinga, 12-XI-1935, Giardelli 128 (SI). Jujuy. Depto. Tumbaya, laguna Volcán, 21-II-2002, Cialdella 522 (SI). La Pampa. Depto. Loventué, Cerro Nevado, 1931, Monticelli 4025 (SI). La Rioja. Depto. Gral. Sarmiento, rumbo salina del Leoncito, 12-XII-1996, Biurrum 4507 (SI). Mendoza. Depto. Las Heras, Paramillo de Uspallata, 6-IV-1945, Covas 18524 (SI). Salta. Depto. Cachi, Pque. Nac. Los Cardones, 14-II-2002, Cialdella 262 (SI). San Juan. Depto. Iglesia, ruta 150, desde Las Flores a Guardia Vieja, 16-I-2012, Sede 501 (SI). San Luis. Depto. La Capital, Cerro La Aguada, 5-XI-1940, Burkart 10921 (SI). Tucumán. Depto. Tafí, Tafí del Valle, cerro Pelado, 25IV-1948, Krapovickas 4583 (BAB).

Salvia cardiophylla Benth., Labiat. Gen. Spec.: 721. 1835. TIPO: [Uruguay] "Banda Oriental", J. Davids s.n. (holotipo K 00479345!). Fig. 3.

Salvia approximata Briq., Bull. Trav. Soc. Bot. Geneve 5: 119. 1889. nom. illeg., non Pau 1887. TIPO: [Paraguay], Luque, 20-III-1875, B. Balansa 989a [lectotipo G 00307522 ! (montado en 2 hojas) aquí designado; isolectotipos BM 000087110!, F 0061173F!, G 00307508!, G 00307519!, K 000479344!, P 00715010!, P 00715008!, P 00715009!].

Salvia cinerarioides Briq., Bull. Trav. Soc. Bot. Ge- 
neve 5: 118. 1889. TIPO: Paraguay, "L'Assomtion, Dans les haies", 10-X-1875, B. Balansa 989 (lectotipo G 00307520! designado por O'Leary \& Moroni, Novon 24: 375. 2016; isolectotipos BR 05113477!, F v0061180F!, G 00307521!, GOET 004440!, K 000479342!, P 00715011!, P 00715007 !, P 00715013 !, P 00715014!, S-R-9021!, UC 001943403!).

Salvia approximata var. kuntzeana Briq., Bull. Herb. Boissier 4: 852. 1896. TIPO: Paraguay, "Paraguay meridional", IX-1892, O. Kuntze s.n. (lectotipo G 00307523! designado por O'Leary \& Moroni, Novon 24: 375. 2016; isolectotipos G 00307524!, NY 00000257!).

Salvia rojasii Briq., Bull. Herb. Boissier, sér. 2, 7: 604. 1907. TIPO: Paraguay, “Gran Chaco, Loma Clavel”, XI-1903, E. Hassler \& T. Rojas 2566 (lectotipo G 00307528! designado por O'Leary \& Moroni, Novon 24: 376. 2016; isolectotipos BM 00087111!, F v0061203F!, G 00307525!, G 00307526!, G 00307527!, G 00307530!, GH 00001849!, K 000479343!, NY 00000381!, P 00715007 !, UC 00950283!, UC 001943402!).

Sufrútice erecto, hasta de $80 \mathrm{~cm}$ de alto, con pubescencia glandular abundante o no. Hojas con pecíolo de 0,2-1,5 cm, lámina de 1-4,5 × 1-3,5 cm, ovado-triangular, ápice agudo, base cordada, margen serrado, pubescencia más densa en cara abaxial con escasos a densos pelos glandulares, a veces con aspecto incano. Flores pediceladas, pedicelo de 2-5 $\mathrm{mm}$, agrupadas en verticilastros de 4-6 flores, reunidos en pseudoracimos terminales laxos de 10-20 $\mathrm{cm}$. Brácteas florales persistentes en antesis, de 4-7 $\mathrm{mm}$, ovadas, pubescentes, no amplexicaules, color verde; cáliz de 7-8 mm, 5-nervado, labio superior ápice entero, labio inferior ápice 2-dentado, pubescencia variable, pelos glandulares en la cara externa, cara interna pubescente en la mitad superior. Corola color celeste claro a lila, con mácula blanca o blanquecina, de 12-15 mm, tubo de 7-8 $\mathrm{mm}$, pubescente en la mitad superior externa, labio superior de 3-5 $\mathrm{mm}$, cóncavo, entero o emarginado, labio inferior de 5-9 mm, trilobado, el medio mayor y emarginado. Estambres inclusos. Estilo exerto, de $10 \mathrm{~mm}$. Clusas de 2-3 mm, elipsoides, trígonas, pardas, lisas o finamente granulosas.

Distribución. Salvia cardiophylla es una especie nativa de América del Sur que se encuentra presente en el norte y centro-este de la Argentina, sur de Brasil, Paraguay y Uruguay.
Observaciones. Si bien Briquet (1889) especifica en el protólogo de Salvia approximata que el ejemplar tipo está depositado en Ginebra $(G)$, en este herbario se encontraron tres duplicados. Se elige como lectotipo el único ejemplar de los tres que posee una etiqueta manuscrita por el autor que dice: "Salvia approximata sp. nov. determ. J. Briquet mar. 1889".

\section{Material representativo examinado}

ARGENTINA. Chaco. s. loc., IX-1917, Jörgensen 2235 (BA, SI). Córdoba. Depto. Gral. San Martín, Villa María, I-1905, Hicken 289 (SI). Corrientes. Depto. Capital, $5 \mathrm{~km}$ E Lag. Bravo, 29-VII-1970, Krapovickas 15839 (BAB). Entre Ríos. Depto. Paraná, IX-1956, Martínez Achebanch 15 (SI). Formosa. Depto. Pilcomayo, Pque. Nac. Pilcomayo, Ea. La Angela, 17-III1992, Fortunato 2754 (BAB, SI). Jujuy. Depto. Capital, Qda. de Lozano, 18-IV-1975, Cabrera 26060 (SI). Misiones. Depto. Capital, Posadas, 23-I-1907, Spegazzini s.n. (BAB 17241). Salta. Depto. Rosario de la Frontera, 21-XII-1948, Argañaráz 749 (LIL). Santa Fe. Depto. La Capital, Isla Timbó, Tedone 5203 (SF).

Salvia coccinea Buc'hoz ex Etl., Comm. Bot.Med. Salvia: 23. 1777. Horminum coccineum (Buc'hoz ex Etl.) Moench, Methodus: 377. 1794. TIPO: Lámina 2, cent. 2, Dec. 3, en Buc'hoz, P. J., Histoire univ. règne vég. 1772 (lectotipo designado por Santos, Bull. Mus. Natl. Hist. Nat., B, Adansonia 1: 155. 1994). Fig. 4.

Salvia pseudococcinea Jacq., Collectanea 2: 302-303. 1788[1789]. Salvia coccinea var. pseudococcinea (Jacq.) A. Gray, Syn. Fl. N. Amer. 2(1): 368. 1878. Salvia coccinea fo. pseudococcinea (Jacq.) Voss, Vilm. Blumengärtn. ed. 3, 1: 839. 1895. TIPO: "In America calidiore crescit", N. J. Jacquin s.n. (holotipo BM 000630626!).

Salvia rosea Vahl, Enum. Pl. 1: 244. 1804. TIPO: India holotipo C 10013208!, "Habitat in India orientali, cutta in horto missionis Tranquebariae, J. P. Röttlen 250" (holotipo C10013208!).

Salvia glaucescens Pohl, Pl. Bras. Icon. Descr. 2: 136, t. 192. 1831. TIPO: Brasil, Goiás, Rio Claro, IV-1821, "habitat in pascuis camporum inter gramina", I. E. Pohl s.n. (lec- 


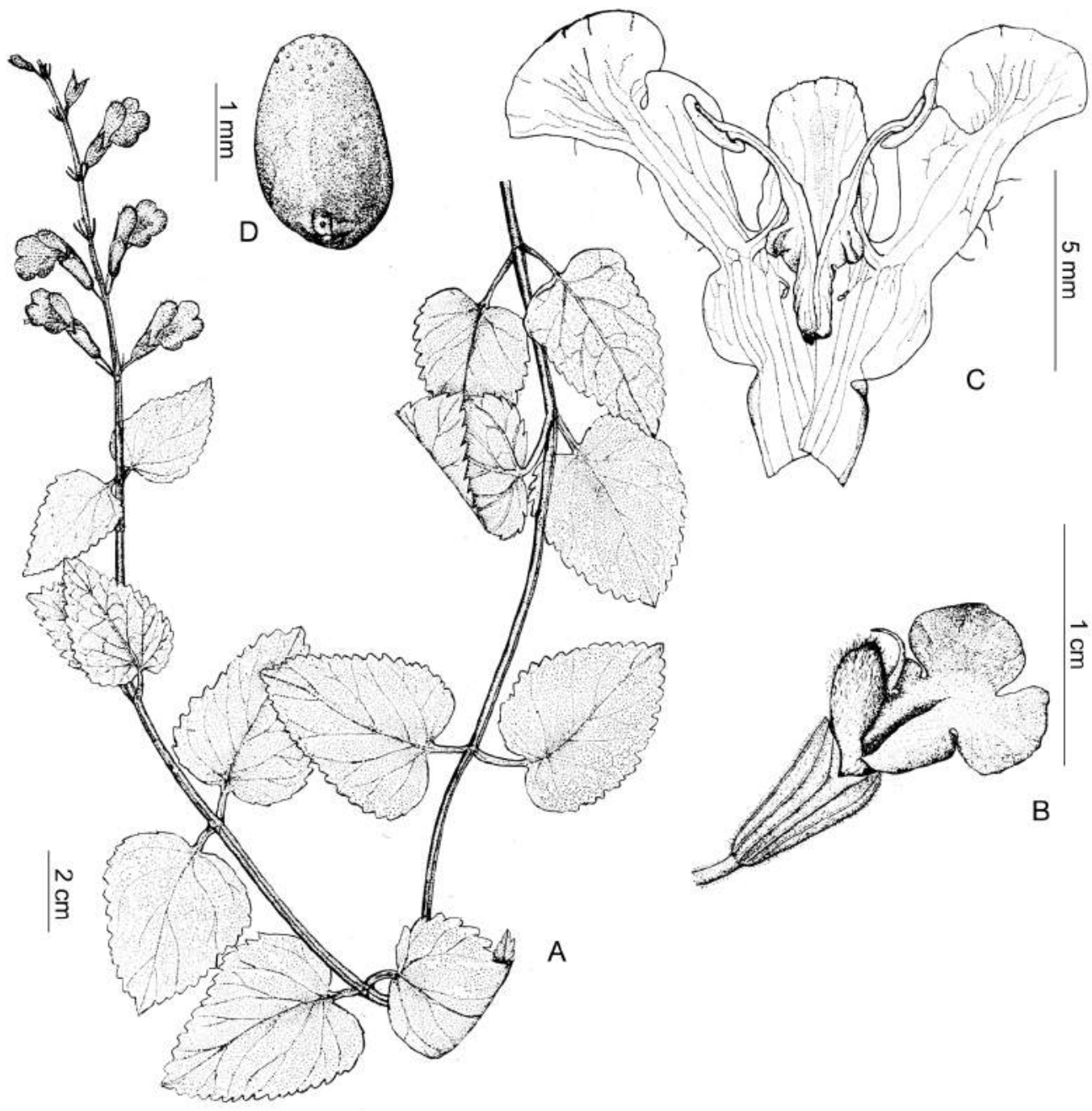

Fig. 3. Salvia cardiophylla. A, aspecto general. B, flor. C, corola extendida. D, clusa. (Tomado con autorización de la Flora de Entre Ríos, Crespo, 1979).

totipo W 0052198! designado por Epling, Repert. Spec. Nov. Regni Veg. Beih. 110: 133. 1939; isolectotipos W 0052199!, W 0052197!).

Salvia ciliata Benth., Labiat. Gen. Spec.: 286. 1833, nom. illeg., non Poir. 1805. TIPO: México, "in dumetis Papantlae Mexicanorum", C. J. W. Schiede \& F. Deppe s.n. (holotipo CGE no visto; isotipo K 00247979!).

Salvia mollissima M. Martens \& Galeotti, Bull. Acad. Roy. Sci. Bruxelles 11(2): 71. 1844. TIPO: México, Oaxaca, "croît dans les endroits humides de Juquila del Sur, près de l'Océan pacifique, à 4500 pieds", Septembre, 1840,
H. Galeotti 657 (holotipo BR 0005112593!; isotipos G 00435418!, P 000714867!).

Salvia galeottii M. Martens, Bull. Acad. Roy. Sci. Bruxelles 11(2): 75. 1844. TIPO: México, "se trouve dans les champs et les prairies de Xalapa à 4000 pieds", H. Galeotti 611 (holotipo BR 0005112951!; isotipo K 000247978!).

Salvia coccinea var. minima Fernald, Proc. Amer. Acad. Arts 35(25): 551. 1900. TIPO: México, Chiapas, table -land about Ocuilapa, alt. 1040-1170 m, 21-VIII-1895, E. W. Nelson 3062 (holotipo GH 00001597!; isotipo US 00121439!). 


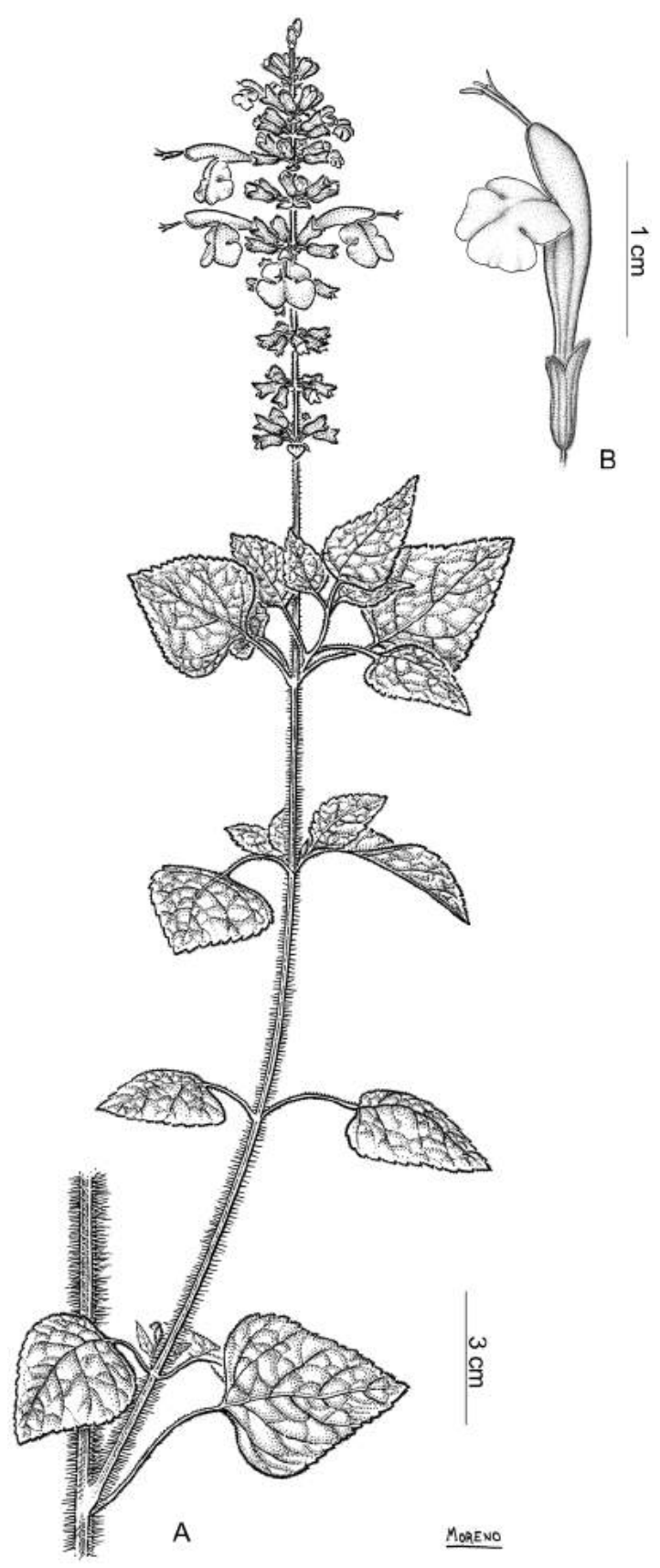

Fig. 4. Salvia coccinea. A, aspecto general. B, flor. De Venturi 260, SI.
Hierba o sufrútice, hasta de $80 \mathrm{~cm}$ de alto, tallos con pubescencia retrorsa y pelos glandulares breves y pelos multicelulares blancos, largos hasta de 3-4 mm, densidad variable. Hojas con pecíolo de 1-2 cm, lámina de 4-7,5 × 1-4,5 cm, cordada o deltada, ápice agudo, base cordada, margen serrado o crenado, pubescencia más densa en cara abaxial. Flores pediceladas, pedicelo de 3-5 mm, con pubescencia retrorsa densa; agrupadas en verticilastros de 4-6 flores, reunidos en pseudoracimos terminales laxos de 10-20 cm. Brácteas florales persistentes en la antesis, de 3-9 mm, ovadas, pubescentes, no amplexicaules, color verde; cáliz de 8-9 mm, 5-6 nervado, labio superior ápice entero, labio inferior ápice 2-dentado, pubescencia híspi$\mathrm{da}$, pelos glandulares de densidad variable en cara externa. Corola color rojo o anaranjado, de 25-26 $\mathrm{mm}$, tubo de $12-17 \mathrm{~mm}$, pubescente en la mitad superior externa, labio superior de 5-7 $\mathrm{mm}$, cóncavo, entero o emarginado, labio inferior de $8-14 \mathrm{~mm}$, tetralobado, los lóbulos centrales más grandes, los laterales pequeños. Estambres exertos. Estilo exerto, de $15 \mathrm{~mm}$. Clusas de 1-3 mm, elipsoides, trígonas, con manchas verdes y púrpuras.

Distribución. Salvia coccinea es una especie nativa de América, presente desde el sur de Estados Unidos de Norteamérica hasta la Argentina y sur de Brasil. Epling (1939) menciona que esta especie se ha convertido en una maleza en áreas tropicales.

\section{Material representativo examinado}

ARGENTINA. Buenos Aires. Pdo. La Plata, Jardín Botánico, 27-IX-1969, Dimitri 326 (SI).

Catamarca. s. loc., 1-II-1910, Spegazzini s.n. (BAB 33419). Córdoba. Depto. Rio Cuarto, Ao. Tegua, ruta 36, 6-IV-1992, Bianco 3778 (RIOC). Corrientes. Depto. La Cruz, 9-XI-1936, Burkart 7941 (SI). La Rioja. Depto. Famatina, 30-IX1903, Burmeister 29 (SI). Misiones. Depto. Montecarlo, Pto. Piray, X-1977, Cabrera 28818 (SI). Salta. Depto. Orán, $800 \mathrm{~m}$ Norte ruta Nac. 50, 19-XI-2001, Fortunato 7396 (BAB). Santa Fe. s. loc., 1906-1907, Schroeter 34 (BA 25559). Santiago del Estero. Depto. Choya, Villa La Punta, Sa. Guasayán, 24-V-1985, Ulibarri 1512 (SI). Tucumán. Depto. Capital, Villa Luján, 1919, Venturi 260 (LIL, SI). 


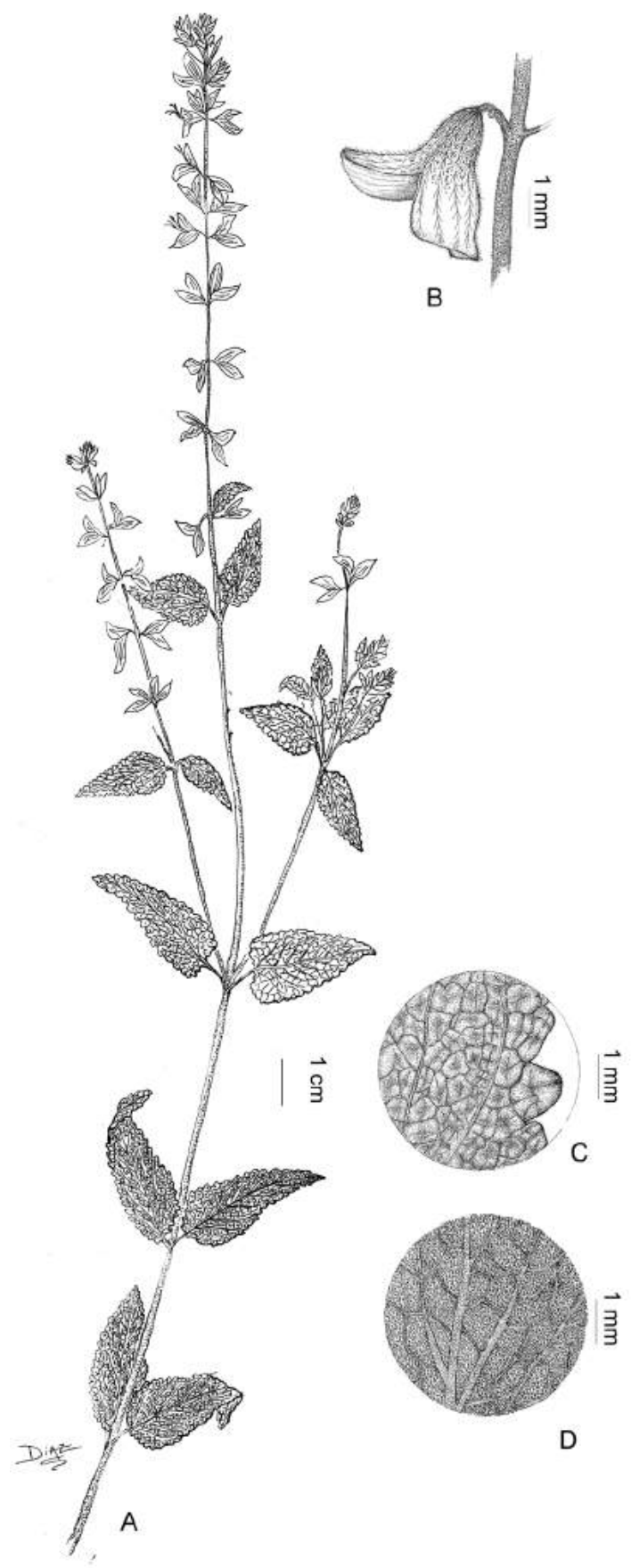

Fig. 5. Salvia cuspidata subp. gilliesii. A, aspecto general. B, cáliz. C, detalle de pubescencia de hoja, cara adaxial. D, detalle de pubescencia de hoja, cara abaxial. A, C y D, de Zuloaga 8443, SI; B, de Cialdella 396, SI.
Salvia cuspidata subp. gilliesii (Benth.) J. R. I. Wood, Kew Bull. 62: 186. 2007. Salvia gilliesii Benth., Labiat. Gen. Spec. 265. 1833. TIPO: Argentina, Mendoza, Gillies s.n. in herb. Bentham (lectotipo K 000479717! designado por Wood, Kew Bull. 62: 186. 2007; isolectotipo E 000399381!, E 00259733!, K 000479720!). Fig. 5.

Salvia lorentzii Griseb., Abh. Königl. Ges. Wiss. Göttingen 19: 239. 1874. TIPO: Argentina, Córdoba, $P$. G. Lorentz 147 (holotipo GOET 00004450!; isotipos BAB 0000274!, CORD 00006147!, F foto 17652 !, K 00479671!, SI 0002120!, UC 001943388!).

Salvia gilliesii var. glandulosa Griseb., Abh. Königl. Ges. Wiss. Göttingen 24: 273. 1879. TIPO: Argentina, Jujuy, P. G. Lorentz \& G. H. E. Hieronymous 769 (holotipo GOET 00004449!; isotipo CORD 00006155!).

Sufrútice ramosos, de $30-150 \mathrm{~cm}$ de alto, tallos ascendentes, pubescencia con pelos fasciculados. Hojas con pecíolo de 0,5-1,5 cm, lámina de 1-5 $\times 1,2-2,5 \mathrm{~cm}$, ovado-deltoide, ápice agudo, base truncada, margen aserrado o crenado, pubescencia canescente en la cara abaxial, nervadura pubescente. Flores pediceladas, pedicelo de 3-5 mm; agrupadas en verticilastros de 3-6 flores, reunidos en pseudoracimos terminales laxos de $5-15 \mathrm{~cm}$. Brácteas florales caducas, de 3-4 mm, ovadas, no amplexicaules, color verde; cáliz de 4-6 mm, hasta $9 \mathrm{~mm}$ en el fruto, 5-6-nervado, labio superior ápice entero, labio inferior ápice 2-dentado, pubescencia variable de pelos uniseriados, con o sin pelos fasciculados largos y laxos, pelos glandulares pedicelados. Corola color azul, con o sin mácula blanca en labio inferior, de $6-15 \mathrm{~mm}$, tubo de 4,5-6 mm, glabro, labios pubescentes en el dorso, el superior de 3,5-5 mm, cóncavo, labio inferior de 4-6 mm, con lóbulo medio orbicular, emarginado, mayor que los laterales. Estambres inclusos. Estilo exerto, de $10 \mathrm{~mm}$. Clusas de 3 $\mathrm{mm}$, elipsoides, ocráceas, finamente reticuladas.

Distribución. Salvia cupidata subp. gilliesii es nativa de América del Sur, está presente en Bolivia y noroeste y centro de Argentina. La subespecie tipo se distribuye por Perú y Bolivia.

Observaciones. Salvia cupidata subp. gilliesii es un taxón muy variable en cuanto a la densi- 


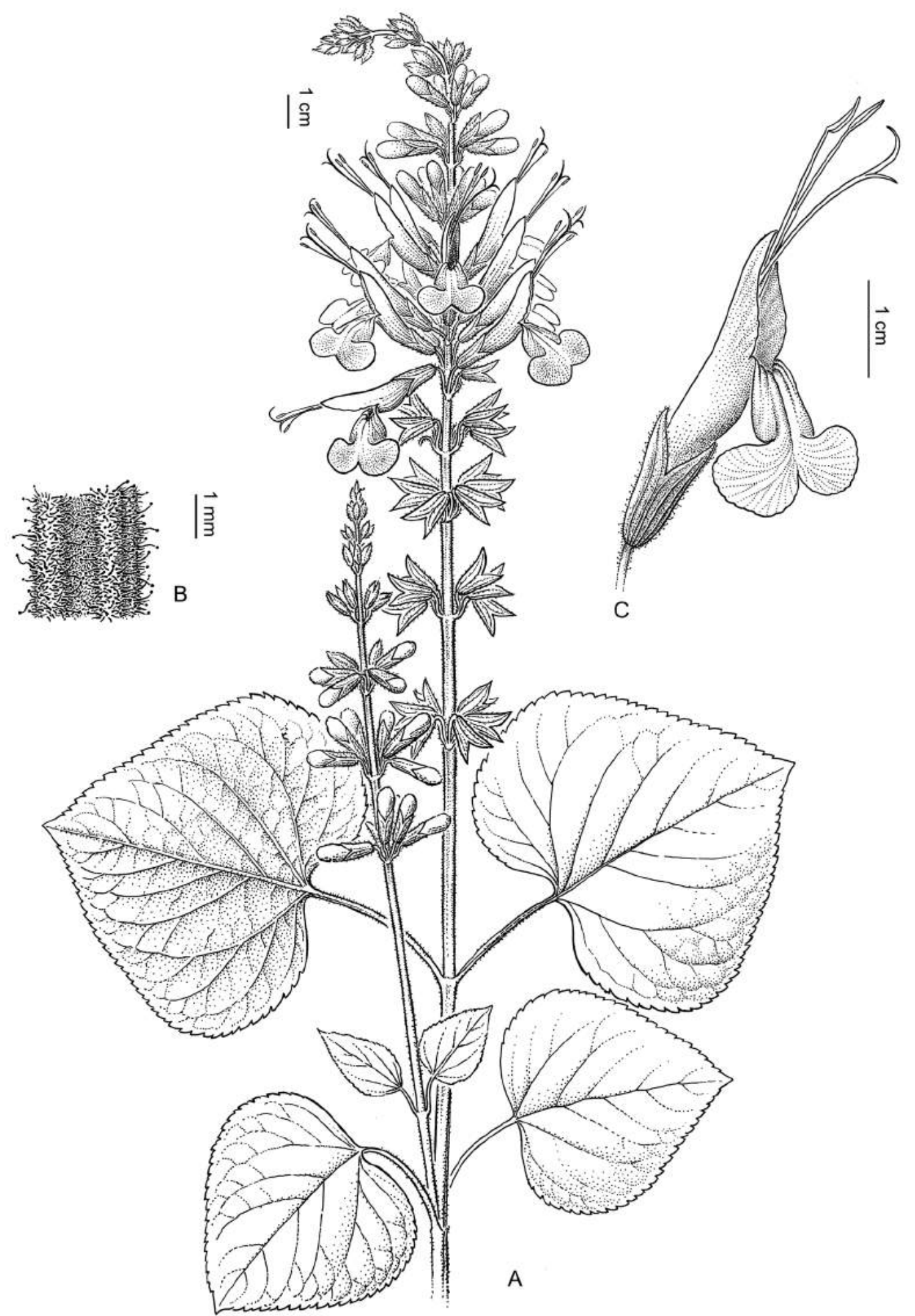

Fig. 6. Salvia exserta. A, aspecto general. B, detalle de pubescencia de tallo. C, flor. De Rodríguez 1463, SI. 
dad de la pubescencia, en ocasiones se encuentran plantas con marcada pubescencia glandular en el cáliz (como por ejemplo el material tipo de Salvia gilliesi var. glandulosa).

Salvia cupidata subp. gilliesii y S. calolophos son los dos únicos taxones argentinos de Salvia con presencia de pelos fasciculados en tallos, hojas y cálices. Se diferencian entre sí porque el cáliz de $S$. cuspidata subp. gilliesii posee pubescencia de pelos uniseriados largos junto con pelos glandulares pedicelados y algunos pelos fasciculados; mientras que el cáliz de $S$. calolophos sólo posee pelos fasciculados breves muy densamente dispuestos. Otra diferencia, aunque no tan constante, es la mayor cantidad de flores por verticilastro en S. calolophos, lo cual le da un aspecto menos grácil a las inflorescencias en comparación con las inflorescencias de S. cuspidata subp. gilliesii.

\section{Material representativo examinado}

ARGENTINA. Catamarca. Depto. Belén, Altivalle de las Granadillas, cerca de Yacutula, II-1872, Lorentz 542 (SI). Córdoba. Depto. Puni1la, La Cumbre, I-1938, Nicora 1790 (SI). Jujuy. Depto. Tumbaya, ruta prov. 79 , de El Moreno a Pueblo Viejo, 12-II-2007, Zuloaga 9297 (SI). La Pampa. Depto. Chical Co, Sierras de Borbarán, cerro de basalto, 21-III-2002, Prina 1646 (SI). La Rioja. Depto. Famatina, Qda. Encrucijada, III-1913, Flossdorf 48 (SI). Mendoza. Depto. Tunuyán, Manzano histórico, 16-III-2011, Deginani 2177 (SI). Salta. Depto. Rosario de Lerma, Qda. del Toro, finca El Lampazar, 14-II-2007, Zuloaga 9329 (SI). San Juan. Depto. Iglesia, Qda. de Agua Blanca, 27-II-1988, Kiesling 6990 (SI). San Luis. Depto. Chacabuco, río Papagayos, 13-XII-1989, Ezcurra 529 (SI). Santiago del Estero. Depto. Choya, Sa. de Guasayán, 27-XII-1989, UIibarri 1759 (SI). Tucumán. Depto. Tafí del Valle, Amaicha, ruta 307, entre Amaicha y El Infiernillo, 12III-2000, Xifreda 2090B (SI).

Salvia exserta Griseb., Abh. Königl. Ges. Wiss. Göttingen 24: 274. 1879. TIPO: Argentina, Jujuy, G. H. E. W. Hieronymus \& P. G. Lorentz 985 (holotipo GOET 0009526!; isotipos CORD 0006159!, F foto 17646!). Fig. 6.
Salvia praeclara Epling, Repert. Spec. Nov Regni Veg. Beih. 85: 121. 1936. TIPO: Bolivia, Mecoya, $R$. Pearce 639 (holotipo K 000479574!).

Hierba anual, de $150 \mathrm{~cm}$ de alto, tallos con pubescencia glandular densa, pringosa. Hojas con pecíolo largo, de 5-10 cm, lámina de 5-15 × 2-15 cm, ovada, ápice agudo, base cordada, margen aserrado, pubescencia estrigosa escasa en ambas caras, márgenes ciliados. Flores pediceladas, pedicelo de 4-6 mm, glanduloso; agrupadas en verticilastros de 4-6 flores, reunidos en pseudoracimos terminales laxos o densos, de $5-30 \mathrm{~cm}$. Brácteas florales caducas, de 3-4 mm, pubescentes, no amplexicaules, color verde; cáliz rojo a la madurez, de 10-15 mm, 5-6 nervado, labio superior ápice entero, acuminado, labio inferior ápice 2-dentado, pubescencia hispido glandular. Corola color rojo, ca. $32 \mathrm{~mm}$, tubo de $10-11 \mathrm{~mm}$, pubescente en la cara dorsal, labio superior de $20 \mathrm{~mm}$, cóncavo, labio inferior mayor, de $28 \mathrm{~mm}$, trilobado, el central mayor y marcadamente bilobado. Estambres exertos. Estilo exerto, de $12 \mathrm{~mm}$. Clusas de $4 \mathrm{~mm}$, fulginosas, lisas.

Distribución. Salvia exserta es una especie nativa de América del Sur, presente en Bolivia y en el noroeste de la Argentina.

\section{Material representativo examinado}

ARGENTINA. Salta. Depto. Sta. Victoria, pie de La Cuesta de Mesón, 12-II-1953, Sleumer 3994 (SI). Tucumán. Depto. Trancas, San Pedro de Colalao, 10-IV-1914, Rodriguez 1463 (BA, SI).

Salvia guaranitica A. St.-Hil. ex Benth., Labiat. Gen. Spec. 298. 1833. TIPO: Brasil, [Rio Grande do Sul:] "Santo Anjo", 1816-1821 (fls.), A. F. C. P. de Saint-Hilaire 2756 (lectotipo P 00715034! designado por O'Leary \& Moroni, Novon 24: 374. 2016; isolectotipos F 0061192!, P 00715033!, P 00715035 !, UC 1943407!). Fig. 7.

Salvia coerulea Benth., Labiat. Gen. Spec. 298. 1833. TIPO: Brasil, sine loc., 1830, F. Sellow s.n. (lectotipo K 000479463 ! designado por O’Leary \& Moroni, Novon 24: 374. 2016; isolectotipo K 000479462!) Salvia coerulea var. regnellii Benth., Linnaea 22: 567. 


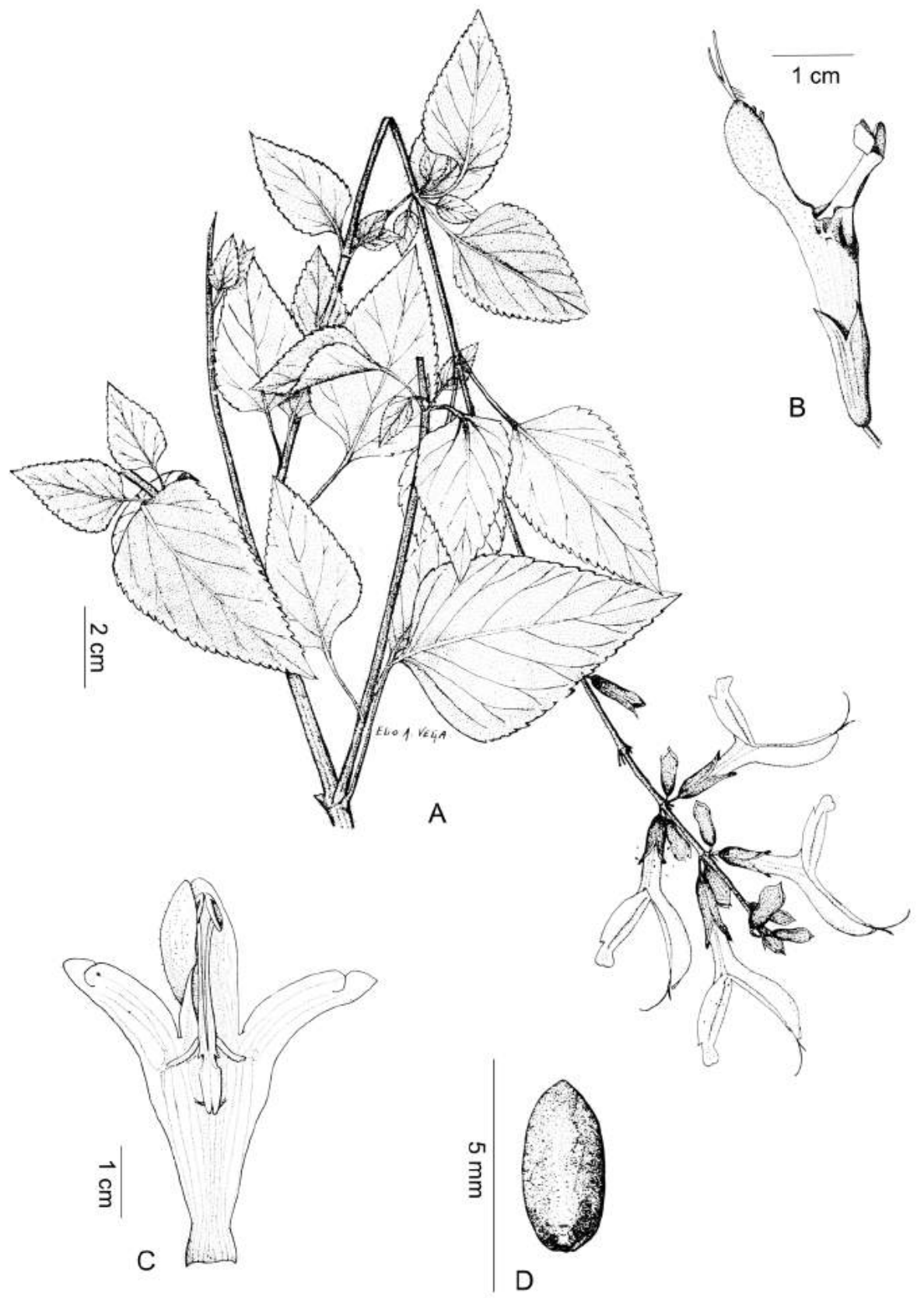

Fig. 7. Salvia guaranitica. A, aspecto general. B, flor. C, corola extendida. D, clusa. (Tomado con autorización de la Flora de Entre Ríos, Crespo, 1979). 

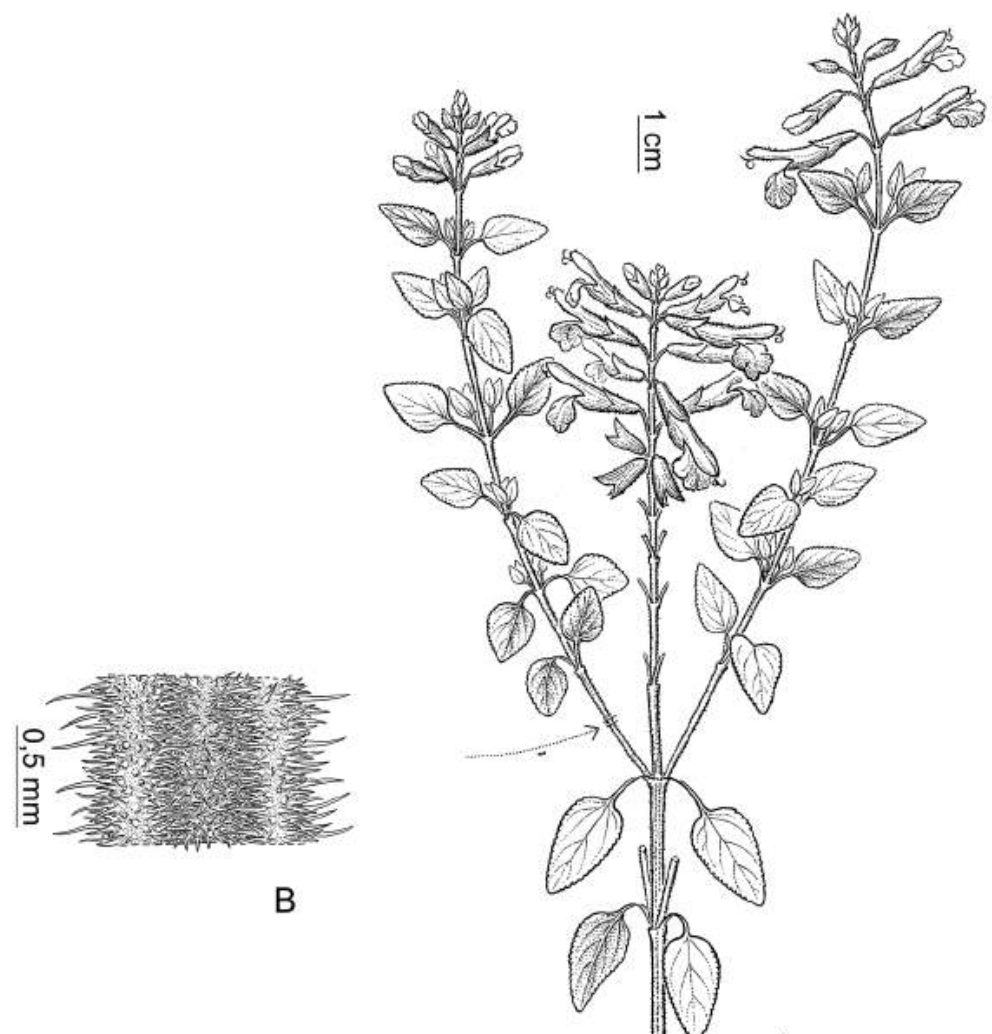

A
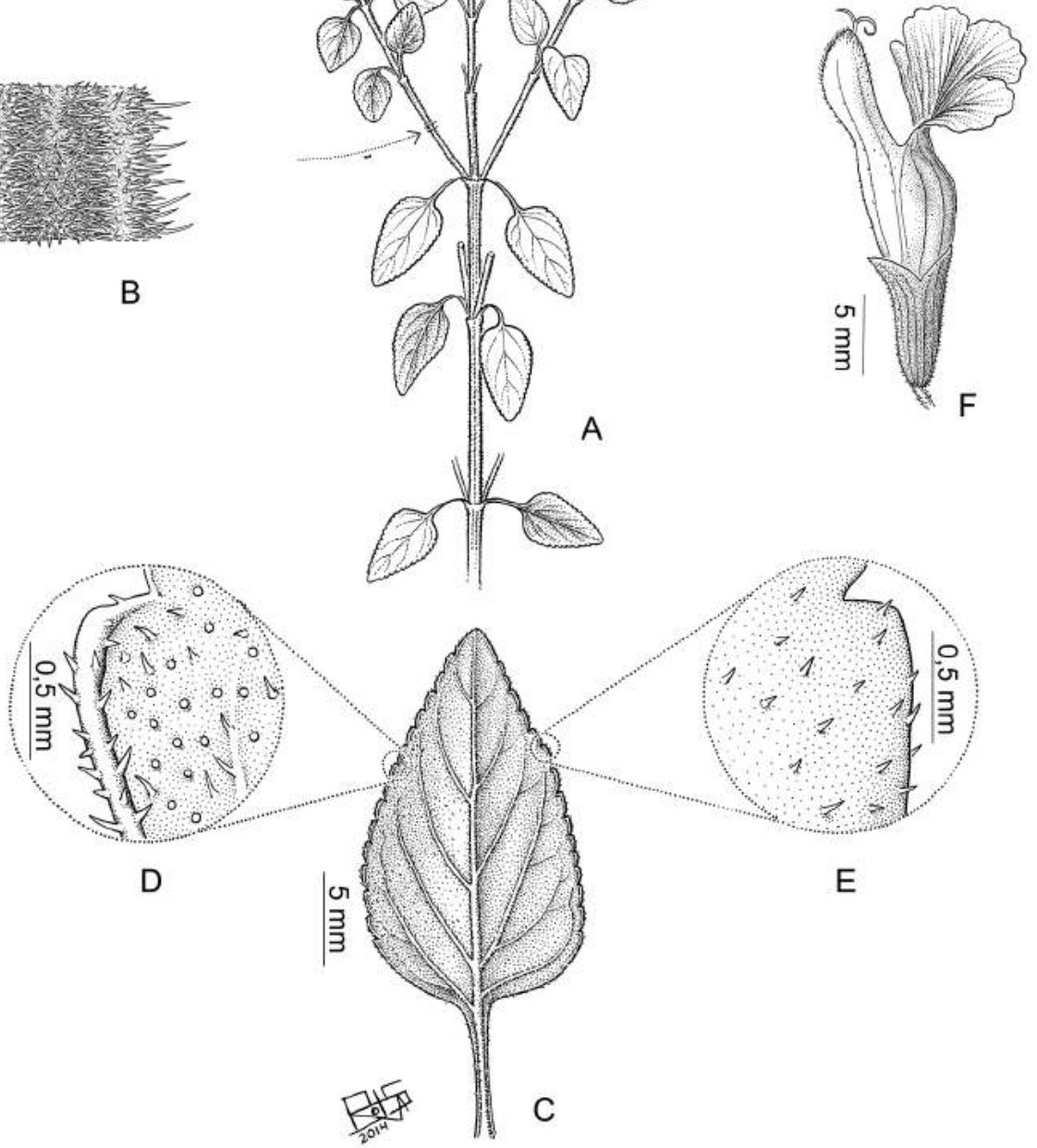

Fig. 8. Salvia microphylla. A, aspecto general. B, detalle de pubescencia de tallo. C, hoja, cara abaxial. D, detalle de pubescencia de hoja, cara abaxial. E, detalle de pubescencia de hoja, cara adaxial. F, flor. De Nicora 679, SI. 
1849. TIPO: Brasil, Minas Gerais, A. F. Regnel 315 (holotipo K 0000479464!).

Salvia ambigens Briq., Bull. Trav. Soc. Bot. Geneve 5: 120. 1889. TIPO: Paraguay, Forêts de Caaguazu, sur les bords des picadas, XI-1874, B. Balansa 991 (lectotipo G 00307518 ! designado por O'Leary \& Moroni, Novon 24: 375. 2016; isolectotipos G 00307517!, P 00715037!, P 00715038!).

Salvia melanocalyx Briq., Bull. Herb. Boissier 4: 862. 1896. TIPO: Argentina, Córdoba (cult.), XII-1891, C.

E. O. Kuntze s.n. (holotipo G 00435536 !; isotipo NY 0000298!).

Arbustos o sufrútices, hasta de $200 \mathrm{~cm}$ de alto, rizomatoso, tallos con pubescencia glandular. $\mathrm{Ho}^{-}$ jas con pecíolo de 0,5-4 cm, lámina de 2-9,5 × 1-6 $\mathrm{cm}$, ovada, deltoide, ápice agudo, base truncada, margen finamente aserrado o crenado, pubescencia más densa en cara abaxial principalmente sobre las nervaduras. Flores pediceladas, pedicelo de 2-5 $\mathrm{mm}$; agrupadas en verticilastros de 6-10 flores, reunidos en pseudoracimos terminales laxos, de 10-20 $\mathrm{cm}$. Brácteas florales caducas, de 4-7 mm, ovadas, pubescentes, no amplexicaules, color verde; cáliz de 12-20 mm, 5-nervado, labio superior ápice entero, acuminado, labio inferior ápice 2-dentado, pubescencia con pelos glandulares en cara externa, cara interna pubescente en la mitad superior. Corola color azul o violeta, de $35-50 \mathrm{~mm}$, tubo de 20 $30 \mathrm{~mm}$, pubescente en la mitad superior externa, labio superior de 10-20 mm, cóncavo, emarginado, labio inferior de 7-18 mm, trilobado, el medio mayor suborbicular. Estambres inclusos. Estilo exerto, ensanchándose hacia el ápice, de $25 \mathrm{~mm}$. Clusas de 2,5-4 mm, elipsoides, trígonas, pardas, finamente granulosas.

Distribución. Salvia guaranitica es nativa del sur de Brasil, Paraguay, Uruguay y Argentina.

Observaciones. Se cultiva como ornamental.

\section{Material representativo examinado}

ARGENTINA. Buenos Aires. Pdo. La Plata, Isla Martín García, Barrio Chino, 10-XII-1993, Hurrell 1591 (SI). Catamarca. Depto. Cayapán, Huillapina, XII-1909, Spegazzini s.n. (BAB 28678). Córdoba. Depto. San Javier, La Población, entre Jacanto y Luyaba, 3-I-1956, Hunziker 11460 (SI).
Entre Ríos. Depto. Rosario del Tala, Altamirano, 14-IV-1963, Soraru 6 (SI). Jujuy. Depto. Santa Bárbara, 15-XII-1962, De la Sota 2975 (BAB). Misiones. Depto. Apóstoles, ruta 203, 25-VIII1978, Cabrera 29479 (SI). Santiago del Estero. sine loc., Argañarás 141 (SI). Tucumán. Depto. Capital, Villa Luján, I-1919, Venturi 109 (BA).

Salvia microphylla Kunth, Nov Gen. Sp. (quarto ed.) 2: 295. 1817[1818]. TIPO: México, "Cresit locis alpinis Novae Hispaniae prope Santa Rosa, Moran et Pachuca", A. J. A. Bonpland \& F. W. H. A Von Humboldt s.n. (holotipo P 00670431!; isotipo P 00714924!). Fig. 8.

Salvia grahamii Benth., Edwards's Bot. Reg. 16: t. 1370. 1830. TIPO: México, "in the neighbourhood of the mines of Tlalpuxahua", J. G. Graham s.n. (holotipo K 00248094!).

Salvia obtusa M. Martens \& Galeotti, Bull. Acad. Roy. Sci. Bruxelles 11(2): 72-73. 1844. TIPO: México, "dans les forêts de la cordillère orientale d' Oaxaca, près de Yavezia, Castrasana et Capulalpan, de 50007000 pieds. fl. rouges. Septembre", H. Galeotti 715 (lectotipo BR 0000005114238! designado por O'Leary \& Moroni, Novon 24: 377. 2016; isolectotipos BR 0000005114542!, P 00714926!).

Salvia lemmonii A. Gray, Proc. Amer. Acad. Arts 20: 309. 1885. TIPO: Estados Unidos de América, Arizona, SW Arizona, in the Huachuca Mountains, 1881, J. G. Lemmon 432 (lectotipo GH 00001554 ! designado por Epling, Repert. Spec. Nov. Regni Veg. Beih. 110: 133. 1939).

Salvia odoratissima Sessé \& Moc., Fl. Mexic. 7. 1892. TIPO: México, sine loc., M. Sessé \& J. M. Mociño 223 (lectotipo MA 0604418 ! designado por O'Leary \& Moroni, Novon 24: 377. 2016; isolectotipo MA 0604420!).

Arbustos o sufrútices, hasta de $120 \mathrm{~cm}$ de alto, tallos frecuentemente muy ramificados, pubescencia glandular breve y densa, nudos híspidos. Hojas pecioladas, pecíolo de 0,5-2 cm, lámina de 1-5 × 1-3 $\mathrm{cm}$, ovada, ápice agudo, base aguda, margen serrado, pubescencia pubérula en cara abaxial. Flores pediceladas, pedicelo de 3-4 mm; agrupadas en verticilastros de 2-4 flores, excepcionalmente con 6 flores en algún nudo, reunidos en pseudoracimos termi- 


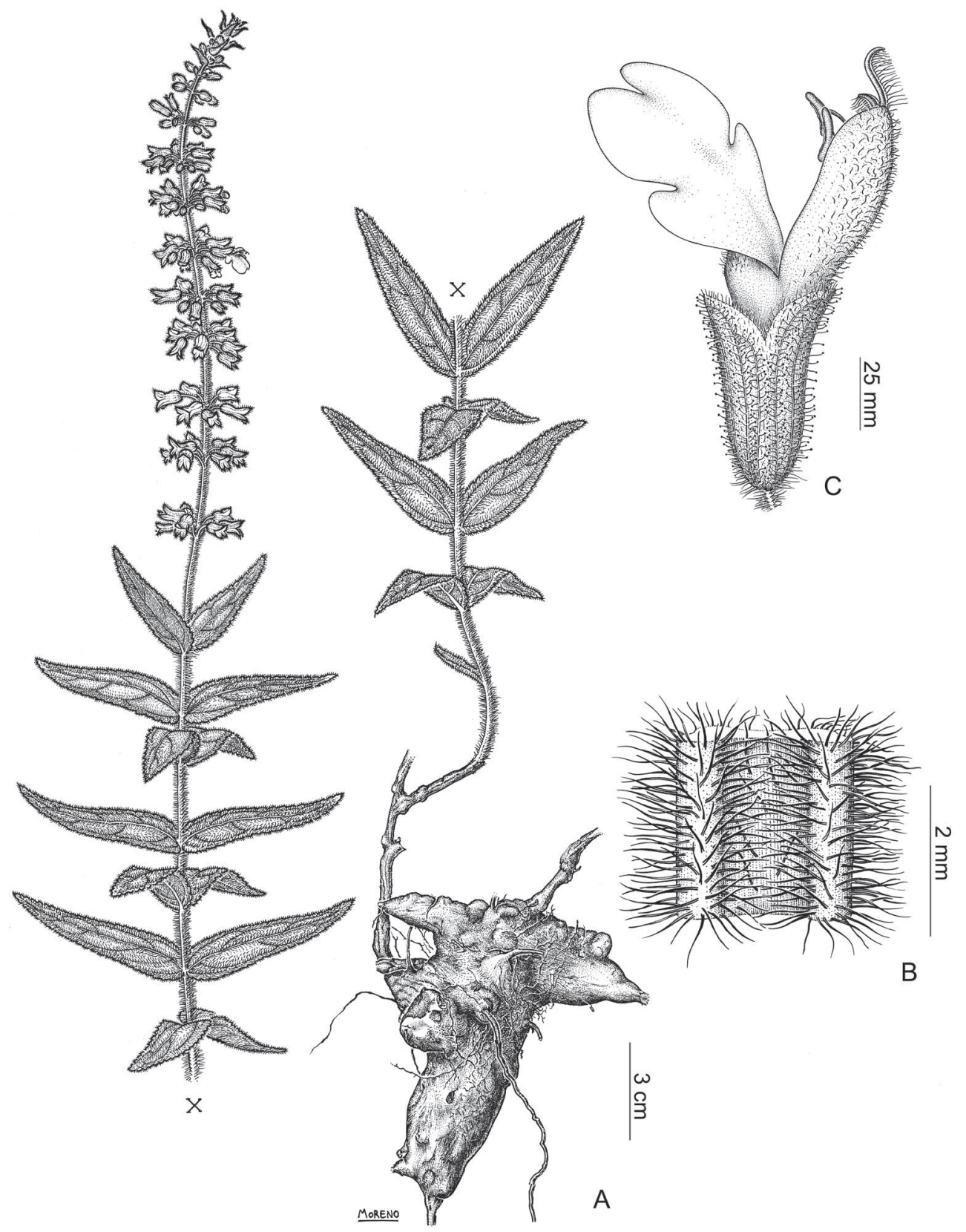

Fig. 9. Salvia nervosa. A, aspecto general. B, detalle de la pubescencia tallo. C, flor. De Cabrera 28182, SI.

nales laxos, de 4-10 cm. Brácteas florales caducas, de 4-6 mm, ovadas, pubescentes, no amplexicaules, color verde; cáliz de 9-11 mm, 6-7-nervado, labio superior ápice entero, labio inferior ápice 2-dentado, pubescencia glandular breve principalmente sobre nervios. Corola color rojo, de $24-26 \mathrm{~mm}$, tubo de 16-17 mm, labio superior de 1-3 mm, entero, labio inferior de 1-3 mm, trilobado, pubescente en el ápice. Estambres inclusos. Estilo exerto, de 25-27 mm. Clusas de 3-43 mm, elipsoides, con manchas pardas. 
Distribución. Salvia microphylla se distribuye desde el sur de Estados Unidos de Norteamérica hasta el norte de América del Sur. En Argentina crece como adventicia, posiblemente escapada de cultivo. También presente en Uruguay.

\section{Material representativo examinado}

ARGENTINA. Buenos Aires. Pdo. Vicente López, Olivos, 20-IV-1947, Stienstra 25289 (SI). Pdo. San Isidro, 1-II-1936, Nicora 679 (SI). Catamarca. Depto. Belén, casa del Padre Urquiza, 17-II-1978, Arenas 243 (BAB, SI). Córdoba. Depto. San Alberto, $2 \mathrm{~km}$ SO de los Hornillos, 28-IV-1984, Hunziker 24787 (BA). Misiones. Depto. San Ignacio, Corpus, 4-II-1900, Gallardo 883 (BA). Salta. Depto. La Viña, 22-II-1990, Novara 9600 (SI). Tucumán. Depto. Tafí, Tafí del Valle, El Mollar, 21-IV-2007, Tracanna s.n. (LIL 608048).

Salvia nervosa Benth., Labiat. Gen. Spec. 268. 1833. TIPO: Brasil, sine loc., X-1823, F. Sellow s.n. (holotipo K 000479334!). Fig. 9.

Salvia lucida Briq., Bull. Trav. Soc. Bot. Genève 5: 118. 1889. Salvia rigida var. lucida (Briq.) Briq., Mém. Soc. Phys. Genève 32(2) 10: 14. 1897. Salvia rigida fo. lucida (Briq.) Briq., Bull. Herb. Boissier, sér. 2, 7: 608. 1907. TIPO: Paraguay, Villa Rica, sur les colines incultes, 18-X-1874, B. Balansa 990 (lectotipo G 00307510! designado por O'Leary \& Moroni, Novon 24: 376. 2016; isolectotipos BR 000005112852!, BR 000005113187!, F v0061197F!, G 00307513!, GOET 004462!, P 00715063!, P 00715062).

Salvia hassleri Briq., Bull. Herb. Boissier, sér. 2, 7: 608. 1907. TIPO: Paraguay, "in campo propre San Estanislao", E. Hassler 4118 (lectotipo G 00307516! designado por O'Leary \& Moroni, Novon 24: 376. 2016; isolectotipos BM 000087123!, G 00307509!, G 00307514!, G 00307515!, GH 00001832!, K 000479337!, MPU 017282!, NY 00000286!, P 00715061!, P 0017282!, W-2361!).

Salvia borjensis E. P. Santos, Biogeographica (The Hague) 71: 22. 1995, nom. nov., non Salvia rigida Benth., 1833, nom. illeg., non Thunb. 1800. syn. nov. TIPO: Brasil, "Brasilia meridionali" F. Sellow s.n. (holotipo K 0000479336!).

Arbustos o sufrútices, de $50-100 \mathrm{~cm}$ de alto, tallos con pubescencia híspida densa, principalmente en los nudos. Hojas sésiles, lámina de 2-6× 1-2 cm, ovado angosta, ápice agudo, base amplexicuale, redondeada a subcordada, textura rugosa-coriácea, margen crenado, cara adaxial glabra, cara abaxial con pubescencia híspida asociada a las nervaduras y hacia la base de la lámina. Flores pediceladas, pedicelo de 2,5-3 $\mathrm{mm}$, agrupadas en verticilastros de 4-6 flores, reunidos en pseudoracimos terminales laxos o densos, de $15-30 \mathrm{~cm}$. Brácteas florales caducas, de $5 \mathrm{~mm}$, elípticas, con pubescencia glandular, no amplexicaules, color verde; cáliz de 4,5-5 mm, 5-nervado, labio superior ápice obtuso, labio inferior ápice 2-dentado, pubescencia glandular de densidad variable. $\mathrm{Co}$ rola color celeste o blanco, de $14 \mathrm{~mm}$, tubo de 9 $\mathrm{mm}$, labio superior de $6 \mathrm{~mm}$, labio inferior de 10 $\mathrm{mm}$, trilobado, el central bilobado. Estambres inclusos. Estilo exerto, de $11 \mathrm{~mm}$. Clusas de 2-2,5 $\mathrm{mm}$, ovoides, ocres, lisas.

Distribución. Salvia nervosa es una especie nativa de América del Sur presente en el este de Paraguay, extremo noreste de Argentina y sur de Brasil.

Observaciones. El análisis del material tipo de $S$. borjensis junto con los materiales determinados para esta especie por Santos, evidencian que lo que Santos (1995) reconoce como S. borjensis se trataría de una variante morfológica de $S$. nervosa de aspecto más grácil. Por otro lado, la mayoría de los ejemplares coleccionados y determinados como $S$. borjensis por Santos pertenecen al departamento de Santo Tomé (Corrientes), lo cual reafirma la idea de que es una variante morfológica con correlación geográfica. En el presente tratamiento se considera un sinónimo de $S$. nervosa.

Salvia rigida Benth. var. cryptocaulos Briq., Mém. Soc. Phys. Genève 32, pt. 2, no. 10: 14. 1897. TIPO: Paraguay, Caaguazú, dans les campos, B. Balansa 990-d (holotipo P 00715064!). Este variedad es ilegítima dado que se basa en el binomio de Bentham que es ilegítimo por homónimo posterior (non Thunb. 1800) (véase bajo Salvia borjensis E. P. Santos).

\section{Material representativo examinado}

ARGENTINA. Corrientes. Depto. Concepción, Tabay, XI-1965, Krapovickas 11689 (SI). Depto. 


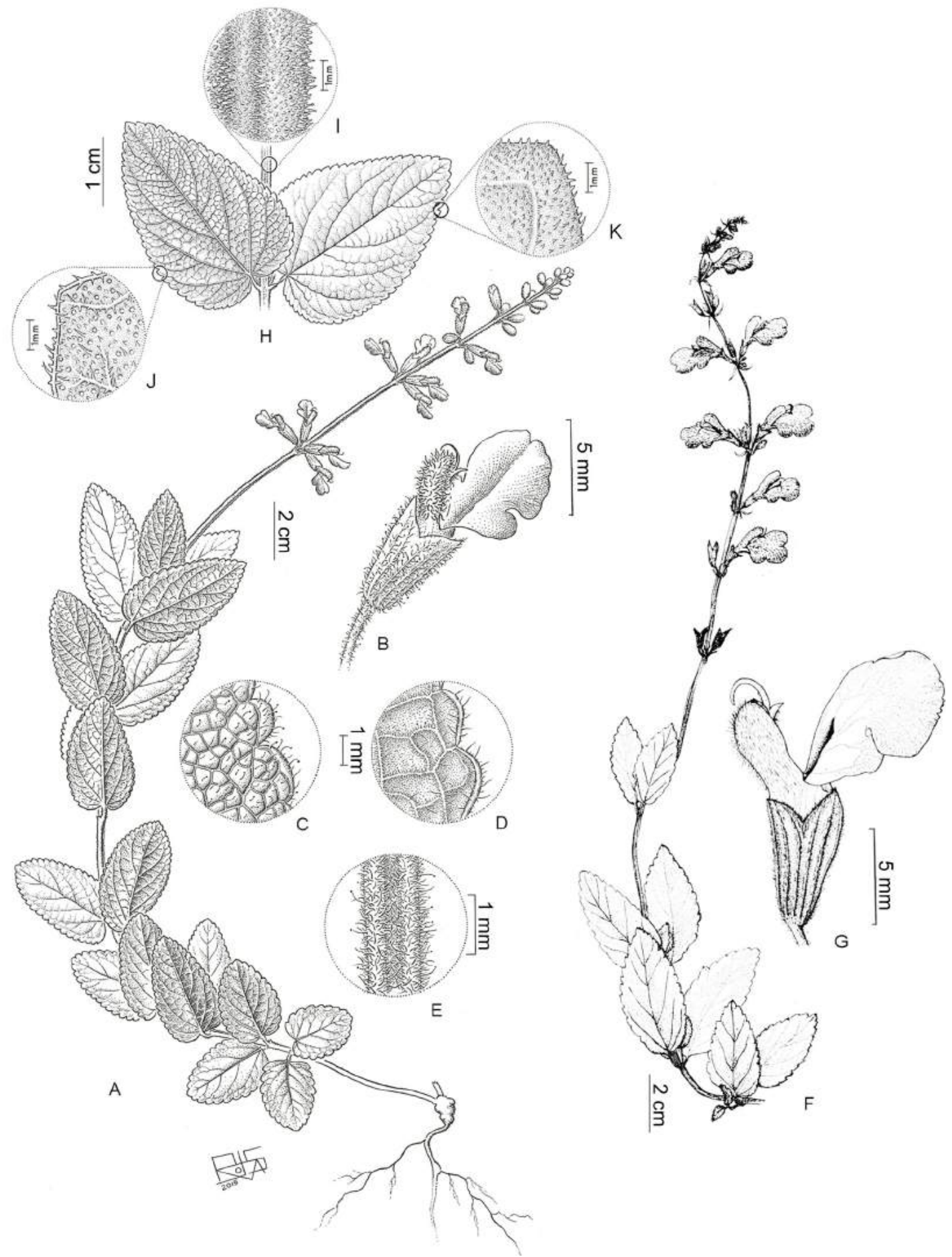

Fig. 10. Salvia ovalifolia var. ovalifolia. A, aspecto general. B, flor. C, detalle de pubescencia de hoja, cara adaxial. D, detalle de pubescencia de hoja, cara abaxial. E, detalle de pubescencia de tallo. Salvia ovalifolia var. villosa. F, aspecto general. G, flor. Salvia ovalifolia var. nitidula. $\mathbf{H}$, detalle de nudo con dos hojas. I, detalle de pubescencia de tallo. J, detalle de pubescencia de hoja, cara abaxial. K, detalle de pubescencia de hoja, cara adaxial. A-E, de Renvoize 3137 , SI; F, G, tomado con autorización de la Flora de Entre Ríos, Crespo, 1979; H-K, de Múlgura 2227, SI. 
Mburucuyá. Ea. Santa Teresa, 28-X-1976, Cabrera 28182 (SI). Depto. Santo Tomé, Ao. Cuay Grande, 5-II-1979, Schinini 16738 (CTES). Misiones. Depto. Concepción, de Concepción de la Sierra a San Javier, 2-II-1945, Sesmero 387 (LIL).

Salvia ovalifolia A. St.-Hil. ex Benth., Labiat. Gen. Spec.: 267. 1833. TIPO: Brasil, Rio Grande do Sul, dans les paturages des Misiones de l'Uruguay, 1816-21 (fls.), A. F. C. P. de Saint-Hilaire Catal. C2, No. 2606 ter (lectotipo P 00715073! designado por O'Leary \& Moroni, Novon 24: 374. 2016; isolectotipos K 00479329!, P 00715074!). Fig. 10.

Sufrútices, de $20-80 \mathrm{~cm}$ de alto, tallos subglabros o con pubescencia híspida o breve, con o sin pelos glandulares. Hojas sésiles, subsésiles, o pecioladas, hasta de $5 \mathrm{~mm}$, lámina de 3-4 × 2-3 cm, ovada, ancha, ápice agudo u obtuso, en ocasiones acuminado, base obtusa a cordada, margen crenado-serrado, textura rugosa-coriácea, cara adaxial subglabra, cara abaxial híspida en las nervaduras y hacia la base. Flores pediceladas, pedicelo de 2,5-3 mm, agrupadas en verticilastros de 4-6 flores, reunidos en pseudoracimos terminales laxos, de 10-20 cm. Brácteas florales caducas o persistentes en antesis, de 8-10 $\mathrm{mm}$, elípticas, con pubescencia glandular, no amplexicaules, color verde; cáliz de 4,5-5,5 mm, 5-nervado, labio superior ápice obtuso, labio inferior ápice 2-dentado, pubescencia glandular. Corola blanca, o color lila, azul, violeta, tubo de 6-9 $\mathrm{mm}$, labio superior de $6 \mathrm{~mm}$, labio inferior de $10 \mathrm{~mm}$. Estambres inclusos. Estilo exerto, de 8-9 mm. Clusas de 2,5 mm, elipsoidales, amarillentas, lisas.

Distribución. Salvia ovalifolia es una especie nativa del este de Paraguay, sur de Brasil, norte de Uruguay y noreste de Argentina, en las provincias de Misiones, Corrientes y Entre Ríos. Crece larguen las margenes de los ríos y en campos y matorrales.

Observaciones. Salvia ovalifolia es un taxón muy variable en cuanto a la morfología foliar; si bien siempre presenta hojas sésiles a subsésiles, de lámina ovado-ancha, el ápice puede ser obtuso u agudo, hasta acuminado, y la base obtusa hasta cordada. Se describen tres variedades principalmente sobre la base de las diferencias en la pubescencia.
Clave para diferenciar las variedades de S. ovalifolia

1. Cáliz sin pelos glandulares

Salvia ovalifolia var. villosa

1. Cáliz con pelos glandulares 2

2(1). Plantas con tallos subglabros o con pubescencia breve con pelos glandulares; hojas subsésiles, pecíolo de 2-5 mm long, ápice obtuso, base obtusa; corolas blancas o color lila Salvia ovalifolia var. nitidula

2. Plantas con tallos con pubescencia híspida con pelos glandulares entremezclados; hojas sésiles o subsésiles, pecíolo hasta de $3 \mathrm{~mm}$ long, ápice obtuso u agudo, en ocasiones acuminado, base obtusa o cordada; corolas blancas o color lila, azul o violeta

Salvia ovalifolia var. ovalifolia

Salvia ovalifolia var. nitidula (Briq.) E. P. Santos, Mém. Soc. Biogéogr. Sér. 3, 4: 17. 1994. Salvia nitidula Briq., Annuaire Conserv. Jard. Bot. Genève 2: 152. 1898. TIPO: Brasil, sine loc., 1835, M. Isabelle s.n. (holotipo G 00435568!). Fig. 10 H-K.

Distribución. Salvia ovalifolia var. nitidula se encuentra en las provincias de Corrientes y Misiones, también citada para el sur de Brasil y Paraguay (Santos, 1996: 56).

\section{Material representativo examinado}

ARGENTINA. Corrientes. Depto. Ituzaingó, ruta 12, Ao. Itaembé, X-1974, Tressens 418 (CTES). Misiones. Depto. Candelaria, Ao. Martín Chico, 24-I-1945, Schwarz 565 (SI). Depto. Loreto, hacia la ruta ruta de Santa Ana a Oberá, 22-IX2000, Mulgura 2227 (SI).

Salvia ovalifolia var. ovalifolia. Fig. 10 A-E.

Salvia durifolia Epling, Repert. Spec. Nov. Regni Veg. Beih. 85: 85. 1935, syn. nov. TIPO: Argentina, Misiones, San Ignacio, Loreto, E. Ekman 1831 (holotipo S-R-5548!; isotipo NY 0000280!).

Observaciones. El material tipo de $S$. durifolia presenta en el mismo ejemplar hojas de ápice agudo acuminado y hojas de ápice obtuso, lo 
cual evidencia que el carácter ápice de la hoja no permite diferenciar taxones. Por otro lado, tanto el material tipo como todos los ejemplares determinados como $S$. durifolia fueron coleccionados en la provincia de Misiones en los departamentos de San Ignacio y Candelaria, lo cual fortalece la idea de que se trata de una variable morfológica con correlación geográfica. En el presente tratamiento se la considera un sinónimo de $S$. ovalifolia var. ovalifolia.

Distribución. Salvia ovalifolia var. ovalifolia crece en el sur de Brasil y Paraguay, y en Argentina en las provincias de Corrientes y Misiones.

\section{Material representativo examinado}

ARGENTINA. Corrientes. Depto. Santo Tomé, X-1977, Cabrera 28400 (SI). Misiones. Depto. Apóstoles, San Jose, Ea. Agrotecnica Don Bosco, 14 -X-1978, Renvoize 3137 (SI). Depto. Candelaria, Loreto, 15-II-1971, Krapovickas 18291 (CTES). Depto. Leandro N. Alem, ruta 14, entre Güemes y San José, 17-XI-2011, Zuloaga 13357 (SI). Depto. San Ignacio, San Igancio, Hostería, 11-I-1976, Krapovickas 28661 (CTES).

Salvia ovalifolia var. villosa Benth., Labiat. Gen. Spec.: 267. 1833. TIPO: Brasil, "Brasil Meridional", F. Sellow s.n. (lectotipo aquí designado G 000435586!). Fig. 10 F-G.

Distribución. Salvia ovalifolia var. villosa crece en Uruguay y en la provincia de Entre Ríos en Argentina.

Observaciones. Santos (1996) menciona como diferencia entre Salvia ovalifolia var. villosa y $S$. ovalifolia var. ovalifolia la presencia de brácteas florales persistentes en la primera, además de la pubescencia no glandular. Sin embargo, las brácteas persistentes o caducas no permite diferenciar variedades pero sí el tipo de pubescencia, y si la misma posee pelos glandulares o no.

Se debió designar un lectotipo para S. ovalifolia var. villosa, ya que que el holotipo de Berlin fue destruido. Se consultaron los herbarios de K, P y G, y solo en $\mathrm{G}$ se encontró material original del taxón, el cual fue elegido como lectotipo.

\section{Material representativo examinado}

ARGENTINA. Entre Ríos. Depto. Concepción del Uruguay, Isletas, 10-IV-1960, Burkart 21894 (SI).

Salvia pallida Benth., Labiat. Gen. Spec.: 250. 1833. TIPO: Brasil, "Brasilia meridionales", F. Sellow s.n. (lectotipo aquí designado $\mathrm{K}$ 0000479324!). Fig. 11.

Salvia serrata Benth., Labiat. Gen. Spec.: 257. 1833. TIPO: Brasil, sine loc., F. Sellow s.n. (lectotipo K 0000479323! aquí designado; isolectotipo HAL 000114371!).

Salvia uruguayensis A. St.-Hil. ex Benth., Labiat. Gen. Spec.: 258. 1833. TIPO: Brasil, [Rio Grande do Sul:] "Bords de l'Uruguay au camp de St Jozé, province de Rio Grande do Sul [in sched.]," 1816-1821 (fls.), $A$. F. C. P. de Saint-Hilaire Catal. C2 No. 2501 (lectotipo P 00715076 ! designado por O'Leary \& Moroni, Novon 24: 375. 2016; isolectotipos P 00715078!, P 00715077!).

Hierba o sufrútice, hasta de $100 \mathrm{~cm}$ de alto, subglabro a pubescente con pelos cortos o largos en entrenudos inferiores. Hojas con pecíolo de 0,4-2 $\mathrm{cm}$, lámina de 1,5-7 × 1-4,5 cm, ovada, ápice agudo, base truncada, margen profundamente crenado o aserrado, pubescencia más densa en los margenes y sobre las nervaduras en cara abaxial. Flores brevemente pediceladas, pedicelo de $3 \mathrm{~mm}$, agrupadas en verticilastros de 6-12 flores, espaciados 2-3 cm entre sí, reunidos en pseudoracimos terminales laxos, de 6-35 cm, de aspecto laxo. Brácteas florales persistentes en antesis, de $2-15 \mathrm{~mm}$, subtriangulares, pubescentes, no amplexicaules, color verde; cáliz de 5-7 mm, 5-nervado, labio superior ápice entero, labio inferior ápice 2-dentado, pubescencia con pelos adpresos en cara externa, cara interna pubescente en la mitad superior. Corola color azul, violeta o celeste, con mácula blanca, de $12-15 \mathrm{~mm}$, tubo giboso de 7-8 mm, pubescente en la mitad superior dorsal, labio superior de 3,5-6 mm, cóncavo, entero o emarginado, labio inferior de 4-13 mm, trilobado, el medio mayor y emarginado. Estambres inclusos. Estilo exerto, ensanchándose hacia el ápice, de 7-8 mm. Clusas de 1,5-3 mm, elipsoides, trígonas, castañas, finamente granulosas. 


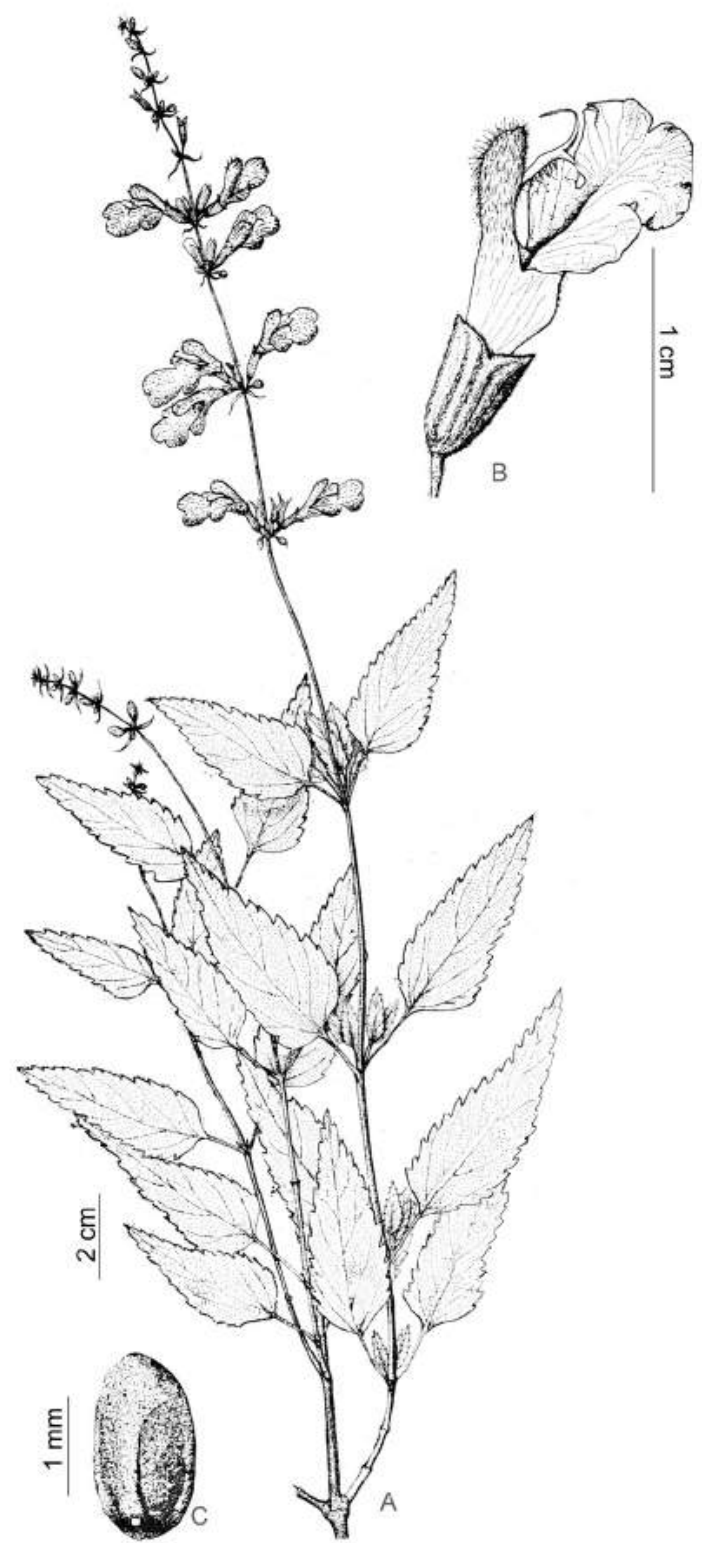

Fig. 11. Salvia pallida. A, aspecto general. B, flor. C, clusa. (Tomado con autorización de la Flora de Entre Ríos, Crespo, 1979).

Distribución. Salvia pallida se distribuye por el sur de Brasil, Paraguay, Uruguay y norte de Argentina hasta Buenos Aires. Crece en campos secos o matorrales.

Nombre vulgar. "albahaca de campo".
Observaciones. Salvia canescens Benth. es un nombre que se encuentra manuscrito en una cartulina en el herbario de Berlin, por lo tanto es ilegítimo. Bentham (1833: 250) lo cita como sinónimo de S. pallida.

Bentham (1833: 257) menciona en el protólogo de Salvia serrata dos ejemplares, uno de Brasil coleccionado por Sellow y depositado en B (ahora destruído, foto $\mathrm{B} \uparrow, \mathrm{F} 17672$ !) y otro ejemplar de Argentina colecccionado por St. Hilaire y depositado en P. Se encontraron duplicados del material de Sellow en K y en HAL. Se elige el material de K como lectotipo. Bentham (1833: 250) explicita que el material tipo de $S$. pallida se encuentra en el herbario B, y menciona dos colecciones: Sellow s.n. (foto B†, F 17659!) y Parker s.n., ambas destruidas. Se elige como lectotipo un duplicado de la colección de Sellow depositado en K.

Se cultiva como ornamental y para cercos vivos.

\section{Material representativo examinado}

ARGENTINA. Buenos Aires. Pdo. La Plata, Isla M. García, IV-1935, Pastore 321 (SI). Chaco. sine loc., IV-1931, Meyer 415 (SI). Córdoba. Depto. Marcos Juarez, ruta 12, 23-II-1966, Hunziker 18654 (BA). Corrientes. Depto. San Roque, ruta nac. 12, 24-II-2006, Denham 116 (SI). Entre Ríos. Depto. Gualequaychú, 5-I-1932, Burkart 4273 (SI). Formosa. Depto. Pilcomayo, Parque Nacional Pilcomayo, X-1991, Fortunato 2056 (SI). Misiones. Depto. Capital, Posadas, I-1930, Rodríguez 13 (BA, SI). Salta. Depto. Orán, camino a Isla de Cañas, 23-XI-2001, Morrone 3979 (SI). Santa Fe. Depto. Rosario, II-1836, Isern 8151 (SI).

Salvia personata Epling, Repert. Spec. Nov. Regni Veg. Beih. 85: 73. 1935. TIPO: Bolivia, Tarija, "loco umbroso humoso", R. E. Fries 1204 (holotipo S-5-10548!; isotipo S-510549!). Fig. 12.

Salvia alba J. R. I. Wood, Kew Bull. 62(2): 210. 2007, syn. nov. TIPO: Bolivia, Tomina, J. R. Wood, D. J. Goyder \& M. Serrano 13311 (holotipo K 00479686!; isotipos HSB no visto, K 00479685!, LPB 000653!, LPB 000654!). 


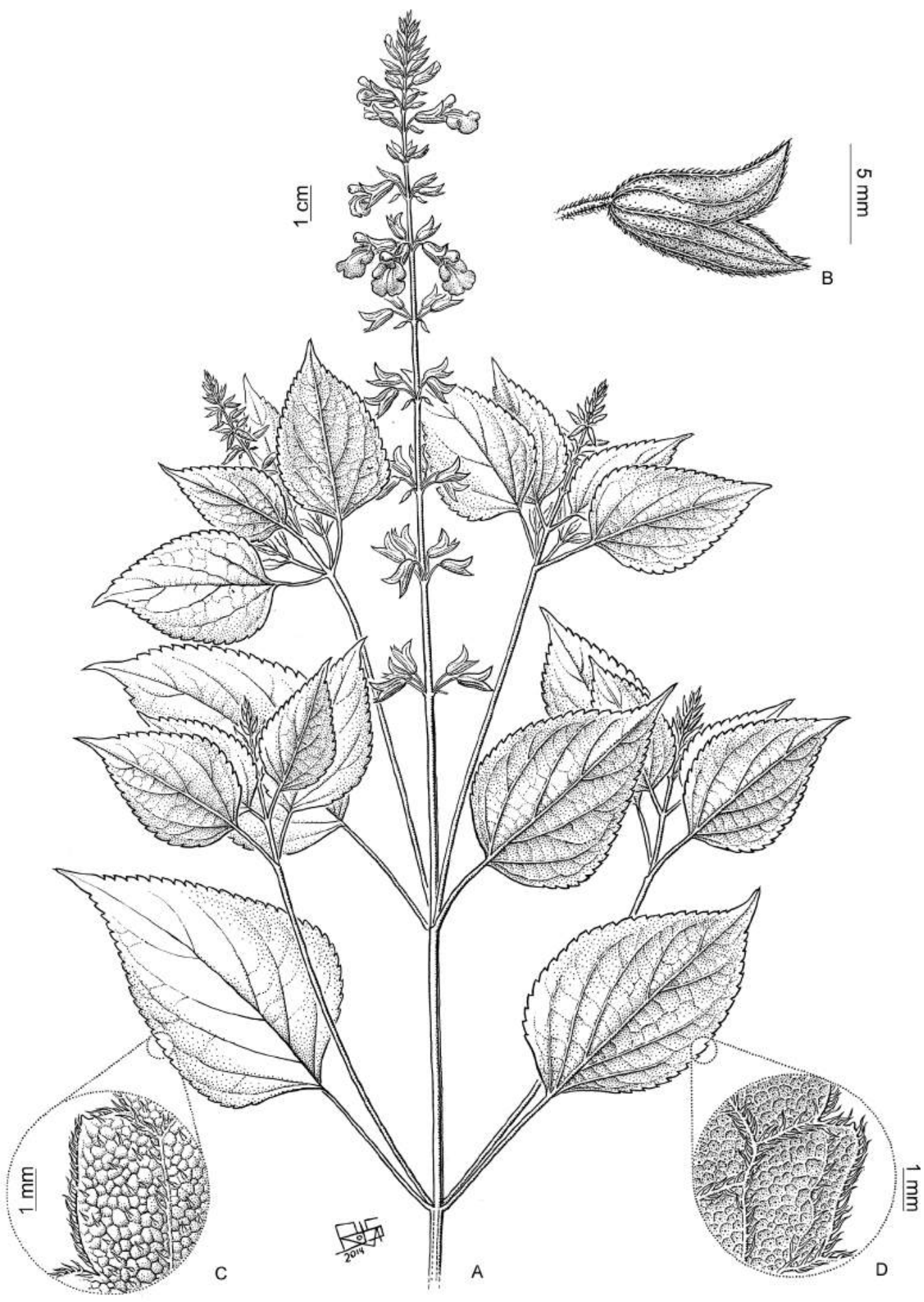

Fig. 12. Salvia personata. A, aspecto general de rama con inflorescencia. B, cáliz. C, detalle de pubescencia de hoja, cara adaxial. D, detalle de pubescencia de hoja, cara abaxial. De Cabrera 30320, SI. 


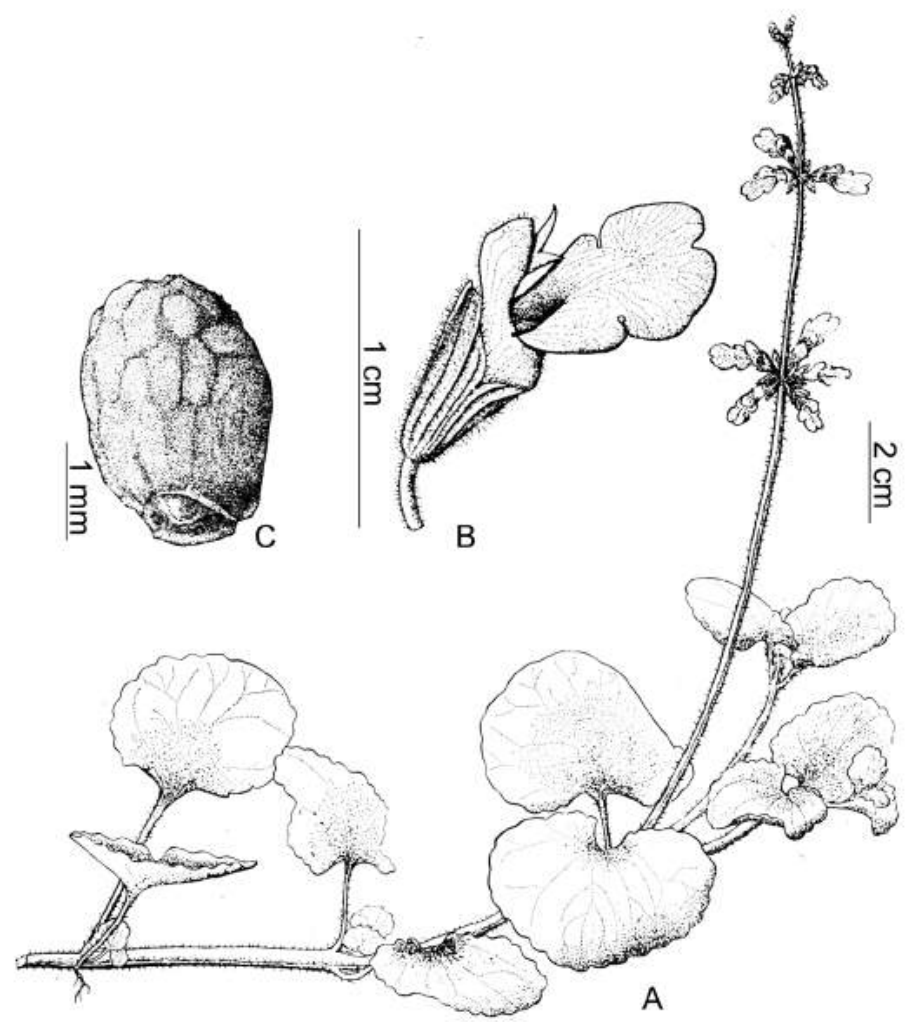

Fig. 13. Salvia procurrens. A, aspecto general. B, flor. C, clusa. (Tomado con autorización de la Flora de Entre Ríos, Crespo, 1979).

Hierba o sufrútice, de 30 a $100 \mathrm{~cm}$ de alto, glabras o con pubescencia escasa. Hojas con pecíolo de 1,5-5 cm, lámina de 5-12 × 3-8 cm, ovada u ovado-elíptica, ápice agudo-acuminado, base redondeada, generalmente asimétrica, margen irregularmente aserrado, pubescencia escasa a densamente pubérula en la cara abaxial principalmente sobre los márgenes y las nervaduras. Flores pediceladas, pedicelo de 4-12 mm, agrupadas en verticilastros de 3-6 flores, espaciados 1-3 cm entre sí, reunidos en pseudoracimos terminales laxos, de $8-30 \mathrm{~cm}$. Brácteas florales caducas, de 4-5 mm, acuminadas, no amplexicaules, color verde; cáliz de 6-10(-13) mm, 3-nervado, acrescente, labio superior ápice entero, labioinferior ápice 2-dentado, con pelos simples a lo largo de los nervios y en el margen. Corola color azul, celeste o blanca, de 10-14 mm, tubo de $9 \mathrm{~mm}$, labio superior de 2-3 mm, cóncavo, labio inferior de 4-5 mm, 3-lobado. Estambres inclusos. Estilo exerto, de $10 \mathrm{~mm}$. Clusas de $2 \mathrm{~mm}$, elipsoides, trígonas, ocráceas.
Distribución. Salvia personata es una especie nativa de América del Sur presente en Bolivia y el noroeste de la Argentina.

Observaciones. Salvia personata y S. splendens se distinguen por la nervación del labio superior del cáliz con tres nervios, mientras que en las restantes especies argentinas de Salvia es de cinco o más nervios. Se diferencia de $S$. splendens porque ésta posee tubo corolino de $27 \mathrm{~mm}$, y en $S$. personata es de $9 \mathrm{~mm}$.

El análisis del material tipo de $S$. alba J. R. I. Wood, junto con la descripción del protólogo, donde se indica como diagnóstico el color blanco de la corola y la densidad de la pubescencia, evidencian que no se puede distinguir de $S$. personata por lo que en el presente tratamiento se la considera un sinónimo.

\section{Material representativo examinado}

ARGENTINA. Catamarca. Depto. Ambato, 
16,5 km rumbo Pucará, 3-IV-1995, Zaravia Toledo 13357 (BAB). Jujuy. Depto. Dr. Manuel Belgrano, de Lagunas de Yala a Termas de Reyes, 11-II-2005, Zuloaga 8670 (SI). Salta. Depto. Candelaria, camino de El Jardín a Pampa Grande, 28-III-2009, Slanis 326 (SI). Tucumán. Depto. Tafí, Alto, 23-I-1924, Venturi 2642 (SI).

Salvia procurrens Benth., Labiat. Gen. Spec.: 266. 1833. TIPO: Brasil, "in Brasilia Meridionali”, F. Sellow s.n. (lectotipo K 00479353! aquí designado; isolectotipos E 00259604!, HAL 00114203!, UC 0001943395!). Fig. 13.

Sufrútices, hasta de $65 \mathrm{~cm}$ de alto, tallos procumbentes, radicantes, pubescencia de pelos glandulares numerosos hacia el ápice. Hojas con pecíolo de 0,5-9 cm, lámina de 1-6,5(-8) × 0,7-8 $\mathrm{cm}$, ovada a suborbicular, ápice redondeado, base cordada, margen ligeramente crenado, pubescencia escasa con pelos sobre las nervaduras en cara abaxial. Flores brevemente pediceladas, éste de 1-3 mm, agrupadas en verticilastros de 6-8 flores, reunidos en pseudoracimos terminales laxos, de $7-12 \mathrm{~cm}$. Brácteas florales persistentes en antesis, de 2-5 mm, ovadas, pubescentes, no amplexicaules, color verde; cáliz de 4-8 mm, inconspícuamente nervado, labio superior ápice entero o ligeramente 3-mucronado, labio inferior ápice 2-dentado, pubescencia con pelos en la cara externa, cara interna brevemente pubescente en la mitad superior. Corola color azul o celeste, con mácula estriada blanca, de $12-15 \mathrm{~mm}$, tubo giboso de $7 \mathrm{~mm}$, pubescente en la mitad superior externa, labio superior de 3,5-4 mm, cóncavo, entero o emarginado, labio inferior de 5-7 $\mathrm{mm}$, trilobado, el medio mayor y emarginado. Estambres inclusos. Estilo exerto, de $8 \mathrm{~mm}$. Clusas de 2,5 mm, elipsoides, trígonas, marrones, finamente granulosas, con surcos oscuros.

Distribución. Salvia procurrens es una espece nativa del sur de Brasil y Uruguay, donde es muy abundante, en Argentina se la encuentra en Buenos Aires y Córdoba.

Observaciones. La descripción de Salvia hederaceae Larrañaga se correspondería con Salvia procurrens, sin embargo el mismo carece de material tipo (comm. pers. M. García, MVM), por lo tanto no es un nombre válidamente publicado.

Bentham (1833: 266) menciona cuatro sintipos en el protólogo de $S$. procurrens, colecciones de St. Hilaire, Sellow, Gillies y Tweedie. Se elige como lectotipo el material de Sellow, porque de los cuatro sintipos es el material más completo y el que se encuentra en más herbarios. Se cuenta adicionalmente con una foto del duplicado destruído de Berlin (foto F 0017662!).

\section{Material representativo examinado}

ARGENTINA. Buenos Aires. Pdo. Zarate, Las Palmas, XI-1951, Boelcke 5100 (SI). Córdoba. Depto. Punilla, Capilla del Monte, Cerro El Zapato, 30-V-1919, Job s.n. (BA 29129).

Salvia reflexa Hornem., Enum. Pl. Hort. Hafn. (Revised ed.): 34. 1807. TIPO: [Localidad desconocida] planta cultivada en el Botanical Garden of Copenhagen a partir de semillas enviadas por Brussonet (lectotipo aquí designado $\mathrm{C}$ 10013249!). Fig. 14.

Hierba anual, de 25-40 cm de alto, pubescencia retrorsa. Hojas con pecíolo de 0,5-1 cm, pubescentes, lámina de 3-4 × 0,5-1 cm, elíptico angosta, ápice obtuso, base aguda, margen espaciadamente serrado, pubescencia abaxial estrigosa densa, adaxial subglabra con pelos glandulares sésiles. Flores brevemente pediceladas, pedicelos de 2 $\mathrm{mm}$, agrupadas en verticilastros de 2-4 flores, espaciados 0,5-1 cm entre sí, reunidos en pseudoracimos terminales laxos, de 10-15 cm. Brácteas florales persistentes, de 4-5 mm, ovada, estrigosas, no amplexicaules, color verde; cáliz de 5-6 mm, 5-nervado, labio superior ápice entero, acuminado labio inferior ápice 2-dentado, pubescencia antrorsa sobre nervios, margen ciliado. Corola color azul o lila, de $9 \mathrm{~mm}$, tubo giboso de $6 \mathrm{~mm}$, pubescente en la mitad superior externa, labio superior de 2 $\mathrm{mm}$, cóncavo, entero o emarginado, labio inferior de $3 \mathrm{~mm}$, trilobado, el medio mayor y emarginado. Estambres inclusos. Estilo exerto, de 7,5-9 mm, ensanchándose hacia el ápice. Clusas de $2 \mathrm{~mm}$, elipsoides, trígonas, ocre finamente granulosas, con surcos oscuros. 


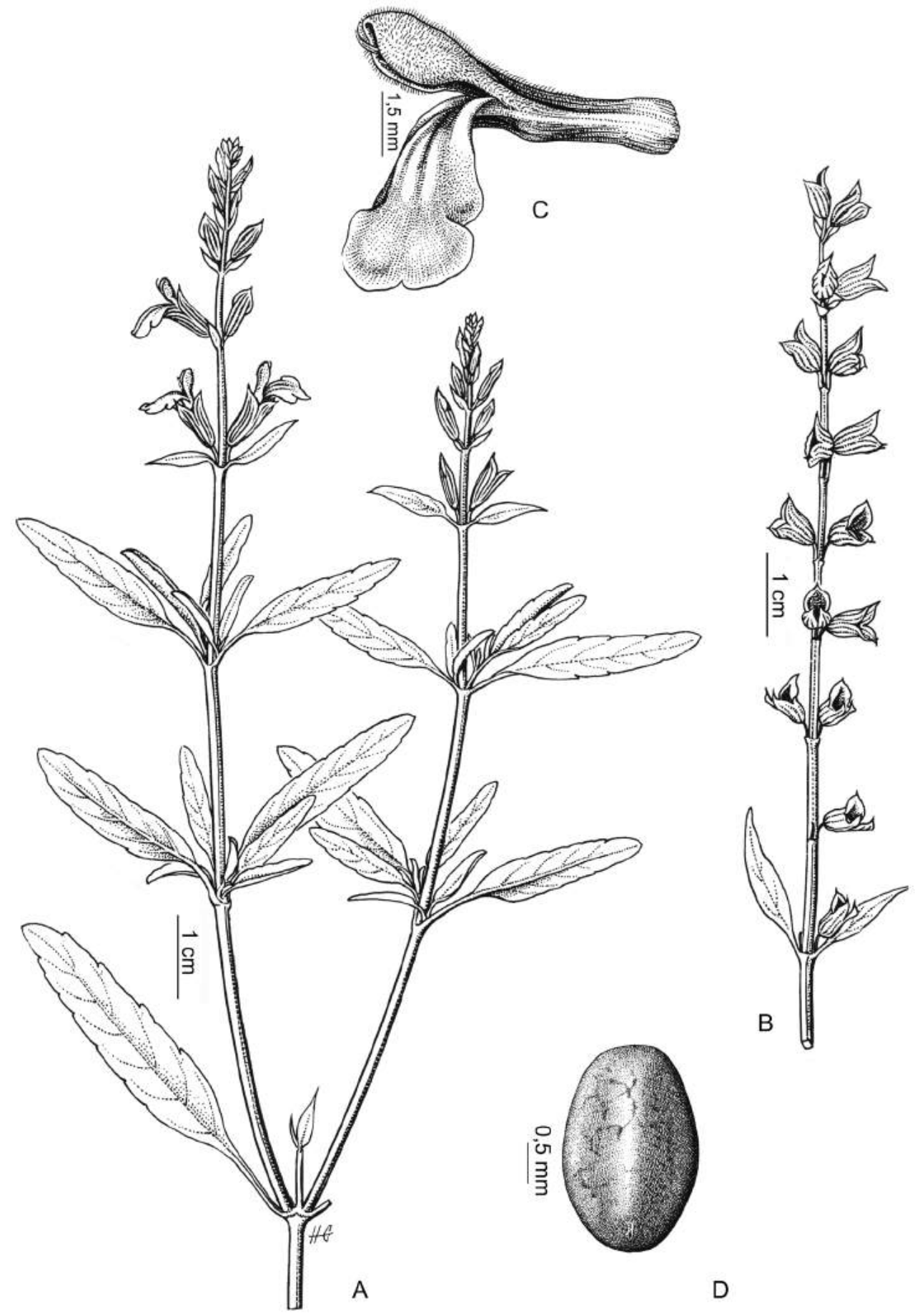

Fig. 14. Salvia reflexa. A, aspecto general. B, detalle inflorescencia. $\mathbf{C}$, corola. D, clusa. (Tomado con autorización y gentileza del Museo Botánico de Córdoba). 


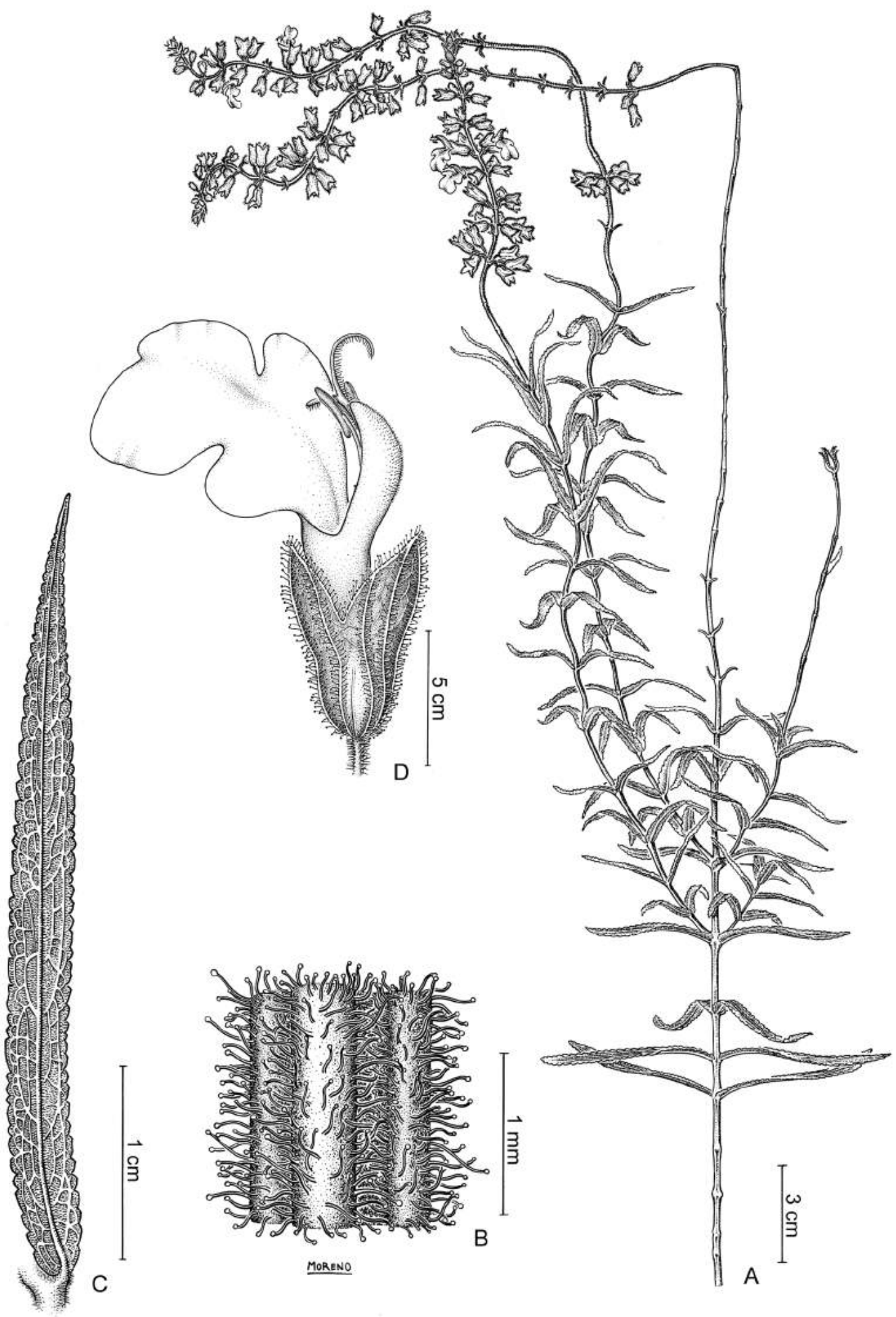

Fig. 15. Salvia rosmarinoides. A, aspecto general. B, detalle de pubescencia del tallo. C, hoja, cara abaxial. D, flor. De Paula-Souza 7226, SI. 
Distribución. Salvia reflexa es una especie nativa de México y Estados Unidos de Norteamérica, se la ha encontrado adventicia en Europa. Se la encuentra como adventicia en la provincia de Córdoba y San Luis, probablemente importada con simiente de cereales y forrajeras (Burkart, 1960: 141; Hunziker, 1961).

Observaciones. Los ejemplares tipo de Hornemann se encuentran depositados en el herbario de Copenhague (Stafleu \& Cowan, 1979). En este herbario se encontró material orginal cultivado que se designa aquí como lectotipo.

\section{Material representativo examinado}

ARGEnTINA. Córdoba. Depto. Punilla, Cosquín, Ea. San Jorge, 20-XII-1955, Fano s.n. (SI 19852). San Luis. Depto. Chacabuco, Nass chel, 19-II-1989, Rosa 972 (BAB).

Salvia rosmarinoides A. St.-Hil. ex Benth., Labiat. Gen. Spec.: 269. 1833. TIPO: Brasil, Rio Grande do Sul, campos des Missions de 1' Uruguay près le Salto, 1816-1821 (fls.), $A$. F. C. P. de Saint-Hilaire Catal. C2, No. 2640 (lectotipo P 00715098! designado por O'Leary \& Moroni, Novon 24: 374. 2016; isolectotipos P 00715099!, P 00715100!). Fig. 15.

Sufrútices, de 40-60 cm de alto, tallos con pubescencia híspida rala con pelos glandulares. Hojas sésiles, lámina de 4-5 × 0,5-1 cm, sublinear, ápice agudo, base amplexicaule, connada, textura rugosa-coriácea, margen crenado, cara adaxial glabra, cara abaxial con pubescencia híspida asociada a la nervadura central. Flores pediceladas, pedicelo de 2,5-3 $\mathrm{mm}$, agrupadas en verticilastros de 4-6 flores, reunidos en pseudoracimos terminales laxos, de 15-30 cm. Brácteas florales caducas, de 7-10 mm, elípticas, con pubescencia glandular, no amplexicaules, color verde; cáliz de $6,5 \mathrm{~mm}$, labio superior obtuso, 5-nervado, inferior 2-dentado, con pubescencia glandular. Corola color azul a celeste, de 12-14 $\mathrm{mm}$, tubo de $9 \mathrm{~mm}$, labio superior de $6 \mathrm{~mm}$, labio inferior de $10 \mathrm{~mm}$. Estambres exertos. Estilo exerto de $10 \mathrm{~mm}$. Clusas de $2 \mathrm{~mm}$, ovoides, ocres, lisas.
Distribución. Salvia rosmarinoides es una planta nativa de América del Sur, presente en sur de Brasil, Paraguay y noreste de Argentina.

\section{Material representativo examinado}

ARGENTINA. Corrientes. Depto. Santo Tomé, Garruchos, 23-III-1977, Cabrera 28288 (SI); ruta 94, $37 \mathrm{~km}$ de límite con Misiones, 14-I-2007, Paula-Souza 7226 (SI). Misiones. Depto. Concepción, 9 km NW C. de la Sierra, III-1969, Krapovickas 15127 (CTES).

Salvia rypara Briq., Bull. Herb. Boissier 4: 850. 1896. TIPO: Bolivia, Sierra de Santa Cruz, V-1892, C. E. O. Kuntze s.n. (holotipo NY 0000313). Fig. 16.

Salvia arenaria A. St.-Hil. ex Benth., Labiat. Gen. Spec.: 257. 1833. TIPO: Brasil, sine loc., A. F. C. P. de Saint-Hilaire s.n. (lectotipo aquí designado $\mathrm{P}$ 00714995!; isolectotipo P 00714996!).

Salvia rhombifolia var. ovata Griseb., Abh. Königl. Ges. Wiss. Göttingen 24: 273. 1879. TIPO: Argentina, Salta, "Ufergebusch bei San José", 1873, P. Lorentz \& G. Hieronymus 218 (holotipo GOET 0004475!; isotipos CORD 0006157!, F 00061202!).

Salvia consimilis Epling, Repert. Spec. Nov. Regni Veg. Beih. 85: 75. 1935. TIPO: Brasil, Paraná, 2-IV-1828, F. Sellow 4518 (holotipo B†, foto F (B neg. 17633).

Salvia australis Epling, Revista Sudamer. Bot. 4: 43. 1937. TIPO: Argentina, Tucumán, Tafí del Valle, "light blue flowers, hab. Faldas del cerro", S. Venturi 86 (holotipo UC 000118!; isotipos BAB 000273!, BAB 000272!, SI 0002133!, SI 0002132!).

Sufrútice, hasta de $120 \mathrm{~cm}$ de alto, tallos ascendentes, ramosos, con pelos glandulares. Hojas con pecíolo de 0,5-2 cm, lámina de 3-8(-10) × 1-2,5($3) \mathrm{cm}$, ovada, ápice acuminado, base redondeada, margen aserrado, pubescencia escasa a densa en ambas caras, acentuada en las nervaduras de la cara abaxial. Flores pediceladas, agrupadas en verticilastros de 3-6 flores, espaciados 1-3 cm, reunidos en pseudoracimos terminales laxos, de $8-15 \mathrm{~cm}$. Brácteas florales caducas o persistentes en antesis, de 2-3 mm, ovadas, acuminadas, no amplexicaules, color verde; cáliz de 5-8 mm, 5-nervado, labio superior ápice entero, labio inferior ápice 2-dentado, 


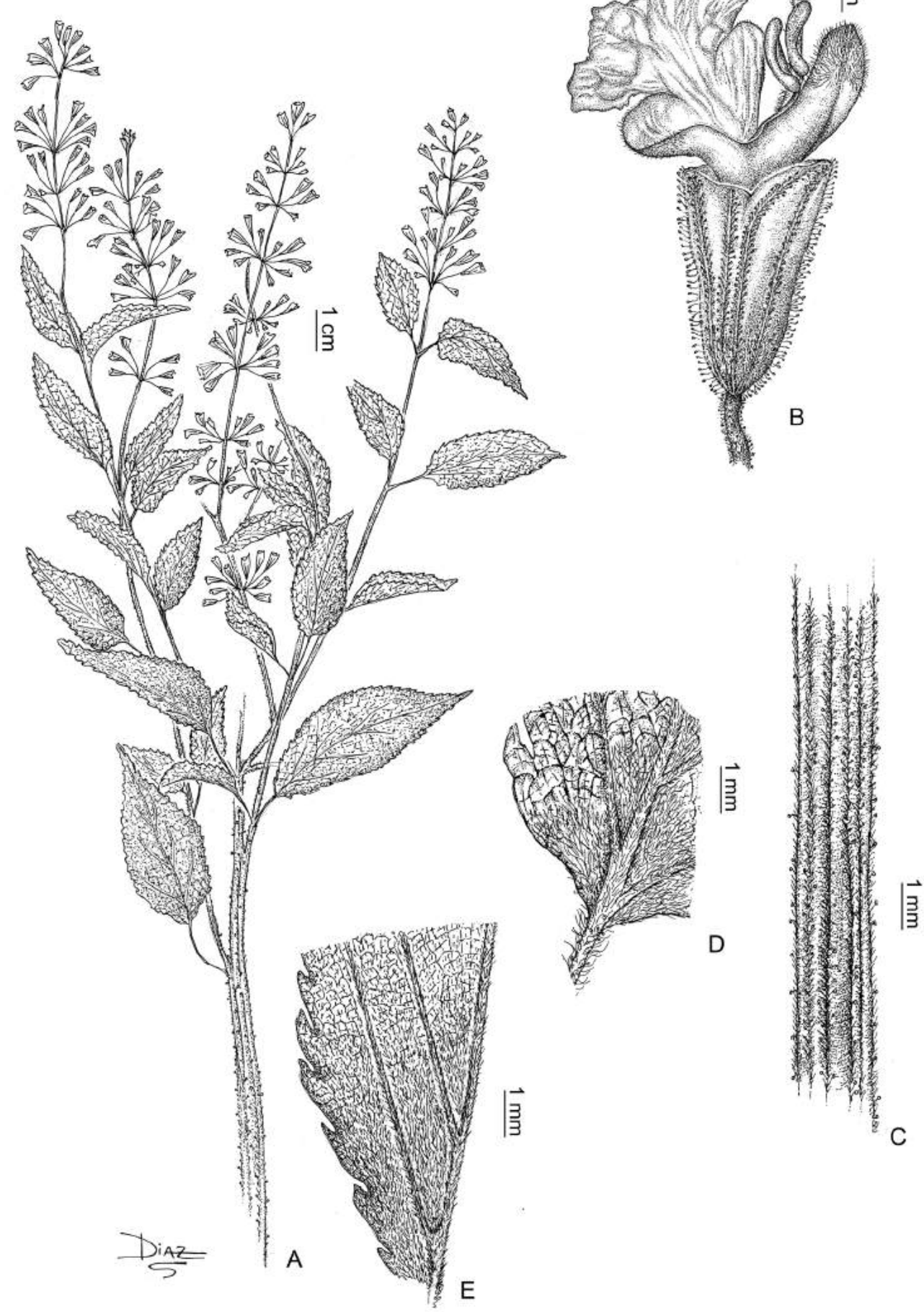

Fig. 16. Salvia rypara. A, aspecto general. B, flor. C, detalle de la pubescencia tallo. D, detalle de pubescencia de hoja, cara abaxial. E, detalle de pubescencia de hoja, cara adaxial. De Zuloaga 8547, SI. 


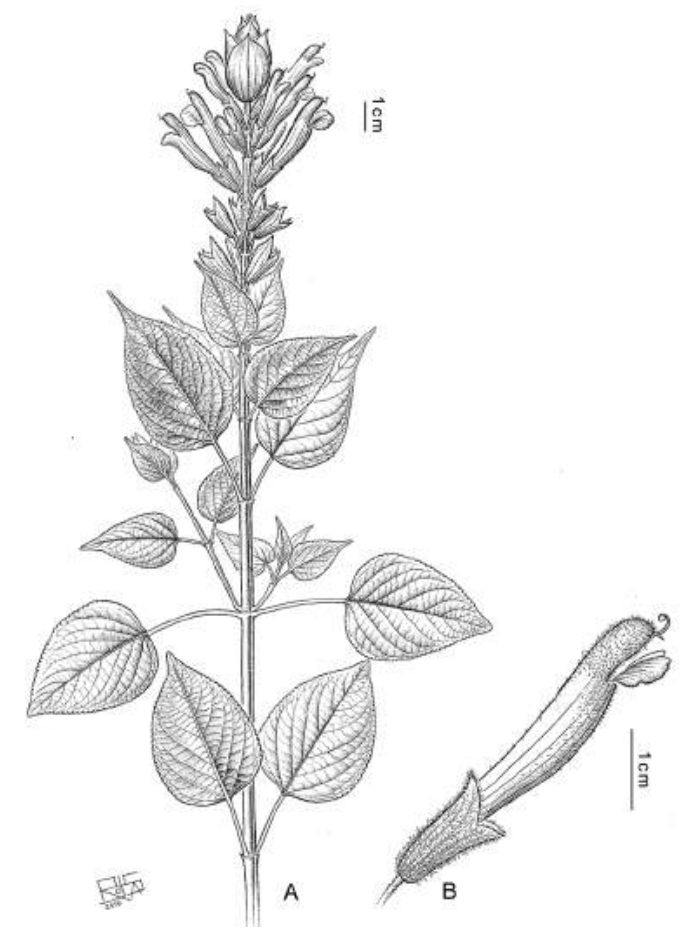

Fig. 17. Salvia splendens. A, aspecto general. B, flor. De Nicora 1423, SI.

pubescencia externa a lo largo de los nervios, con pelos glandulares, pubescencia interna en la parte superior. Corola color azul, con mácula blanca, de 12-15 mm, tubo giboso en la mitad superior dorsal de 5-8 mm, labio superior de 3,5-4 mm, cóncavo, emarginado, labio inferior de $6 \mathrm{~mm}$. Estambres inclusos. Estilo exerto, de $9 \mathrm{~mm}$. Clusas de $3 \mathrm{~mm}$, elipsoides, amarillentas, lisas.

Distribución. Salvia rypara es una especie nativa de América del Sur presente en el noroeste de la Argentina y Bolivia.

Observaciones. S. rypara es una especie muy variable en cuanto a las dimensiones foliares, existiendo ejemplares con hojas grandes, hasta de 10 $\mathrm{mm}$, y otros con hojas pequeñas, hasta de $3 \mathrm{~mm}$; a su vez también es muy variable la densidad de los pelos.

En el herbario P se encontraron dos duplicados correspondientes al ejemplar tipo de Salvia arenaria coleccionado por A. de Saint-Hilaire, por lo cual se elige el ejemplar P00714995 como lectotipo.
La foto del holotipo destruido de Salvia consimilis posee una etiqueta que dice Salvia argutifolia Epling, siendo este último un nombre no publicado. Asimismo posee otra etiqueta que dice "S. arenaria A. St.-Hil.", que es un nombre válido, que luego se consideró sinónimo de este taxón.

\section{Material representativo examinado}

ARGENTINA. Catamarca. Depto. El Alto, Villa del Alto, 16-XII-1976, Kiesling 1277 (SI). Jujuy. Depto. Sta. Bárbara, XII-1986, Zuloaga 2829 (SI). Salta. Depto. Orán, XII-2007, Queiroz 13354 (SI). Tucumán. Depto. Capital, río Salí, X-1920, Venturi 982 (SI).

Salvia splendens Sellow ex Nees, Flora 4(19): 300. 1821. TIPO: [Brasil], "Um Cabo Frio Von Sellow" (lectotipo BR 0006586973! designado por O’Leary \& Moroni, Novon 24: 377. 2016). Fig. 17.

Sufrútice, hasta de $150 \mathrm{~cm}$ de alto, tallos glabros, ramificados, verdes a pardos frecuentemente tornándose rojizos, con pelos diminutos. Hojas con pecíolo de 1-3,5(-6) cm, lámina de 4-10 × 2-8 cm, ovada, ápice acuminado, base obtusa, asimétrica, margen aserrado, pubescencia escasa en ambas caras, acentuada en las nervaduras de la cara abaxial. Flores pediceladas, pedicelos de $2-4 \mathrm{~mm}$, con pubescencia densa de pelos largos, multiseriados; agrupadas en verticilastros de 3-6 flores, espaciados 1-3 cm, reunidos en pseudoracimos terminales densos, de 10-12 cm. Brácteas florales caducas, de 6-20 mm, ovadas, acuminadas, no amplexicaules, color verde; cáliz de 20-22 mm, color rojizo, 3 -nervado, labio superior ápice entero, labio inferior ápice 2-dentado, glabro excepto en los nervios y hacia la base con pelos multiseriados. Corola color rojo, de $35 \mathrm{~mm}$, tubo de $27 \mathrm{~mm}$, giboso en la mitad superior dorsal, labio superior de 7-8 mm, cóncavo, emarginado, labio inferior de $6 \mathrm{~mm}$, trilobado. Estambres apenas inclusos. Estilo exerto de $25 \mathrm{~mm}$. Clusas de $3 \mathrm{~mm}$, elipsoides, pardas, lisas.

Distribución. Salvia splendens es nativa del sureste de Brasil, pero fue introducida por primera vez a la horticultura europea en el siglo XIX y hoy es cultivada como ornamental en regiones tropica- 


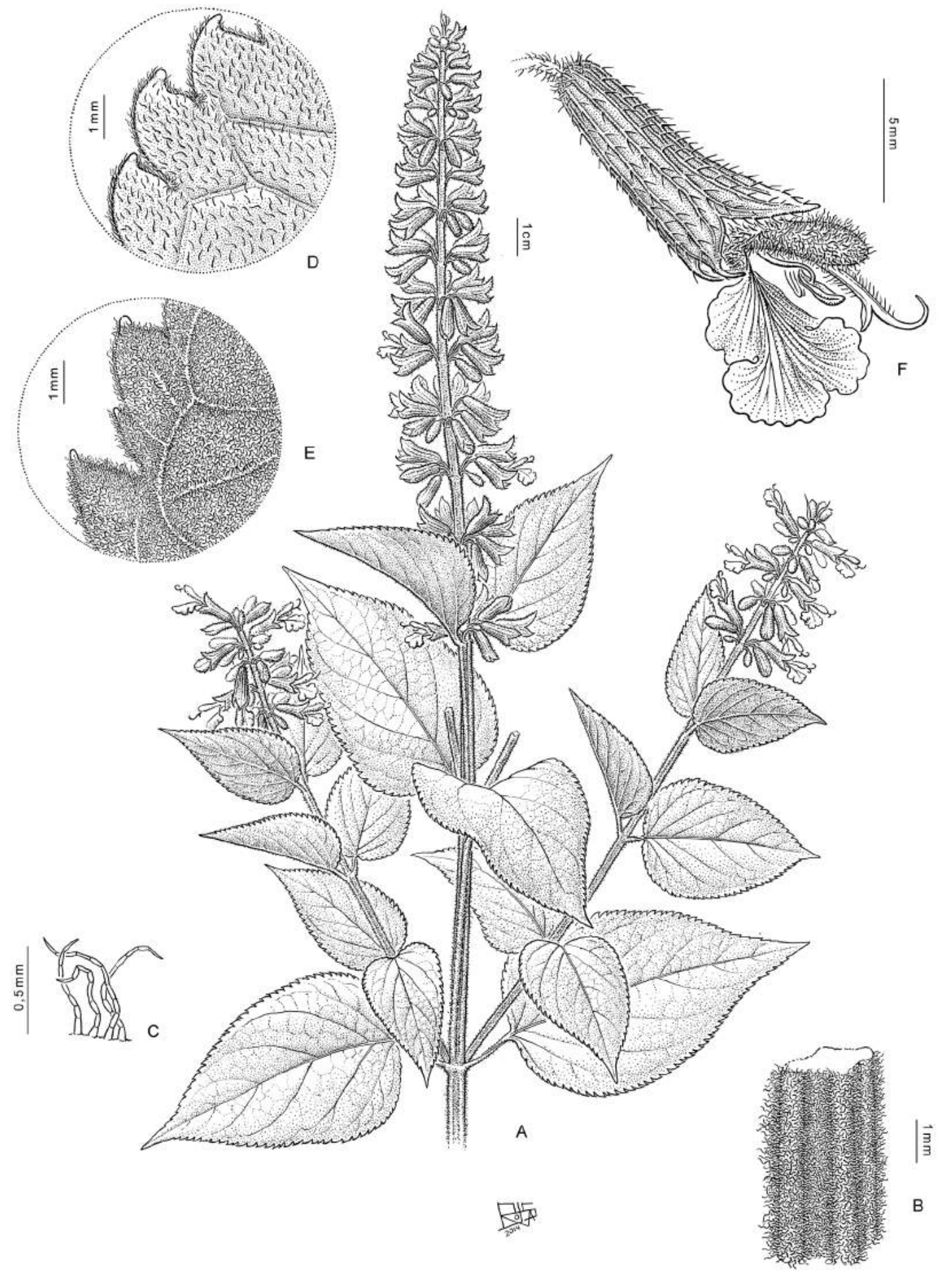

Fig. 18. Salvia stachydifolia. A, aspecto general. B, detalle de pubescencia del tallo. C, detalle de pelos multiseriados. D, detalle de pubescencia de hoja, cara adaxial. E, detalle de pubescencia de hoja, cara abaxial. F, flor. De Xifreda 2095, SI. 
les y templadas de todo el mundo. En Argentina es adventicia, y se la encuentra en Buenos Aires y Tucumán, posiblemente escapada de cultivo.

Observaciones. Salvia splendens Sellow ex Wied-Neuw., Reise Bras. 1: 46. 1820, es un nomen nudum.

\section{Material representativo examinado}

ARGENTINA. Buenos Aires. CABA, Facultad de Agronomía, 20-V-1937, Nicora 1423 (SI). Pdo. Quilmes, II-1914, Holmberg 353 (SI). Tucumán. Depto. Trancas, San Pedro de Colalao, IV-1914, Rodriguez 1460 (SI).

Salvia stachydifolia Benth., Prodr. 12: 311. 1848. TIPO: [Bolivia, Chuquisaca], A. C. V. M. D. D'Orbigny 1281 (lectotipo aquí designado K 000479541!; isolectotipos P 00715120!, P 00715121 !, TCD 000528!). Fig. 18.

Salvia rhinosina var. arborescens Griseb., Abh. Königl. Ges. Wiss. Göttingen 19: 240. 1874. TIPO: Argentina, Tucumán, "in convalle principali pr. Juntas et Anfama“, P. G. Lorentz 417 (holotipo CORD 00006151!).

Salvia rhinosina Griseb., Abh. Königl. Ges. Wiss. Göttingen 19: 239. 1874. TIPO: Argentina, Catamarca, "in montibus alpestribus Granadillas", P. G. Lorentz 571 (lectotipo GOET, designado por Epling, Repert. Spec. Nov Regni Veg. Beih. 110: 202. 1939; isolectotipo CORD 00006149).

Salvia matico Griseb., Abh. Königl. Ges. Wiss. Göttingen 19: 239. 1874.. TIPO: Argentina, Tucumán, Tafi, "non raro in pascuis pr. Cienega", P. G. Lorentz 111 (lectotipo GOET 007389! designado por Epling, Repert. Spec. Nov Regni Veg. Beih. 85: 82. 1937; isolectotipos CORD 00006148!, GOET 007391!, GOET 007390!).

Salvia matico var. cuneata Griseb., Abh. Königl. Ges. Wiss. Göttingen 24: 274. 1879. TIPO: Argentina, Tucumán, Pr. La Ciénega, P. G. Lorentz \& G. H. E. W. Hieronymus 720 (holotipo GOET 0007392!; isotipo CORD 0006158!).

Sufrútice, hasta de $250 \mathrm{~cm}$ de alto, raíz tuberosa, tallos erguidos, en la parte superior pubescencia densa híspida, de pelos multiseriados. Hojas con pecíolo de 1-4 cm, lámina de 5-10 × 2-7 cm, ova- da, ápice acuminado, base redondeada o truncada, margen aserrado-crenado, cara adaxial con pubescencia escasa o glabra, cara abaxial densamente cano pubescente en especial sobre las nervaduras. Flores pediceladas, pedicelo de $2-5 \mathrm{~mm}$, pubescente; agrupadas en verticilastros de 6-12 flores, espaciados 0,5-1 cm, reunidos en pseudoracimos terminales densos, de $15-20 \mathrm{~cm}$. Brácteas florales caducas, de 5-15 mm, ovadas, no amplexicaules, color verde; cáliz de 6-14 mm, acrescente, 5-nervado, labio superior ápice entero, labio inferior ápice 2-dentado, pubescencia híspida sobre los nervios, glabro o escasamente pubescente en la cara interna. Corola color azul, violeta, con mácula blanca, de 13-25 mm, tubo giboso en el dorso, pubescente en la mitad superior dorsal, de $12 \mathrm{~mm}$, labio superior de $7 \mathrm{~mm}$, cóncavo, emarginado, pubescente, labio inferior glabro de $9 \mathrm{~mm}$. Estambres inclusos. Estilo exerto, de $15 \mathrm{~mm}$. Clusas de 2,5-4 mm, elipsoides, amarillentas, punteadas y finamente reticuladas.

Distribución. Salvia stachydyfolia es una especie nativa de América del Sur presente en Bolivia y el noroeste de la Argentina.

Observaciones. Bentham (1848: 311) menciona una colección en el protólogo: “In Peruvia ( $D^{\prime} \mathrm{Or}$ bigny n. 1821)". Se designa como lectotipo el material depositado en el herbario $\mathrm{K}$ donde Bentham trabajó (Stafleu \& Cowan, 1976). Se encontraron varios isolectotipos de esta colección en diferentes herbarios. El ejemplar fue coleccionado en Chuquisaca (Bolivia), como puede leerse en las etiquetas de algunos de los duplicados (P00715121), pero en aquella época esta localidad pertenecía a "Peruvia".

\section{Material representativo examinado}

ARGENTINA. Catamarca. Depto. Andalgalá, Capillitas, II-1959, Diers 64 (SI). Jujuy. Depto. Ledesma, Parque Nacional Calilegua, Aguas Blancas, II-1986, Iudica 223 (SI). Salta. Depto. Cachi, Ruta 33, II-2006, Múlgura 4143 (SI). Tucumán. Depto. Tafí, III-2000, Xifreda 2095 (SI).

Salvia subrotunda A. St.-Hil. ex Benth., Labiat. Gen. Spec.: 290. 1833. TIPO: Brasil, Minas Gerais, 1816-1821 (fls.), A. F. C. P. de Saint-Hilaire Catal. B1, No. 1024 (lectotipo P 00715122! designado 

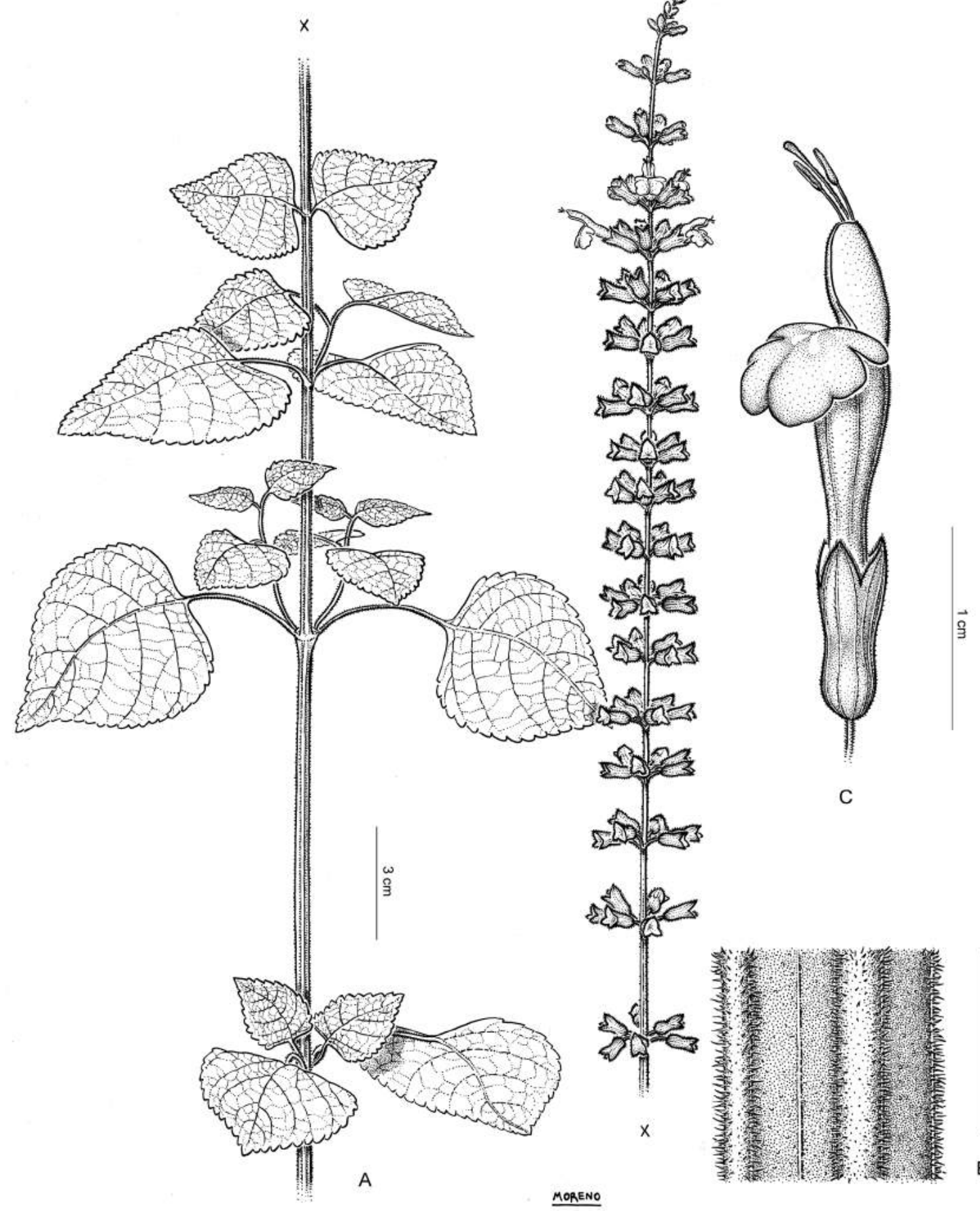

C

Fig. 19. Salvia subrotunda. A, aspecto general. B, detalle de pubescencia del tallo. C, flor. De Guaglianone 2937 , SI. 


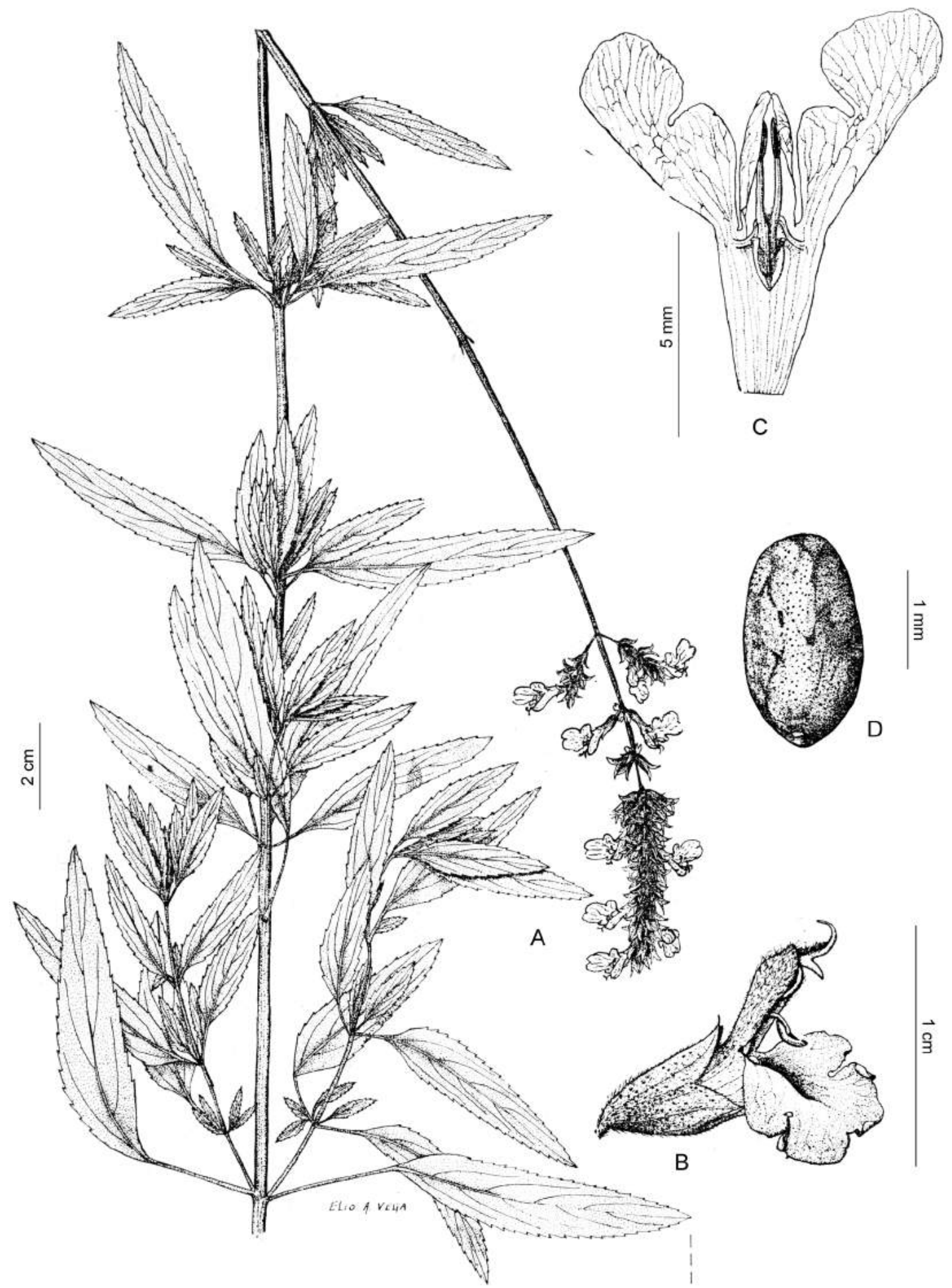

Fig. 20. Salvia uliginosa. A, aspecto general. B, flor. C, corola extendida. D, clusa. (Tomado con autorización de la Flora de Entre Ríos, Crespo, 1979). 
por O'Leary \& Moroni, Novon 24: 374. 2016; isolectotipos P 00715123!, P 00715124!). Fig. 19.

Salvia micheliana Briq. ex Micheli, Mém. Soc. Phys. Genève 32(pt. 2, no. 10): 10, pl. 55. 1897. TIPO: Paraguay, "Ad silvestrum margines prope Costa-Pu$\mathrm{cu}$, inter Paraguari et Ibitimi, April", B. Balansa 1156 (lectotipo P 00715125! designado por O'Leary \& Moroni, Novon 24: 377, 2016; isolectotipo $\mathrm{P} 00715126$ !).

Sufrútice, hasta de $100 \mathrm{~cm}$ de alto, tallos ramificados, glabros a ligeramente pubérulos. Hojas con pecíolo de 3-4,5 cm, láminas de 4-8 x 4-6 cm, ovadas, ápice acuminado, base truncada, margen aserrado, subglabras a pubescencia escasa en ambas caras, acentuada en las nervaduras de la cara abaxial. Flores pediceladas, pedicelos de 5-6 mm, híspidos; agrupadas en verticilastros de 4-6 flores, espaciados 1-2 cm, reunidos en pseudoracimos terminales de $15-20 \mathrm{~cm}$. Brácteas florales caducas, de 4-5 mm, ovadas, acuminadas, no amplexicaules, color verde; cáliz de 6-7 mm, 5-7-nervado, labio superior ápice entero, labio inferior ápice 2-dentado,glabro, ligeramente pubérulo sobre nervaduras. Corola color rojo, de 20-22 mm, tubo de $15 \mathrm{~mm}$, labio superior de $4 \mathrm{~mm}$, cóncavo, emarginado, labio inferior de 2-3 mm, trilobado. Estambres exertos. Estilo exerto, de $15 \mathrm{~mm}$. Clusas de 2-3 mm, elipsoides, pardas, lisas.

Distribución. Salvia subrotunda es nativa del sur de Brasil, este de Paraguay y noreste de Argentina en las provincias de Misiones y Corrientes.

\section{Material representativo examinado}

ARGENTINA. Corrientes. Capital, 6-XI-1986, Charpin 20185 (SI). Misiones. Depto. San Pedro, 18 km NE de Tobuna, 3-II-1976, Romanczuk 695 (SI).

Salvia uliginosa Benth., Labiat. Gen. Spec.: 251. 1833. TIPO: Brasil, sine loc., F. Sellow s.n. (lectotipo aquí designado K 00479352 !; isolectotipo K 00479350!). Fig. 20.

Arbusto o sufrútice, hasta de $200 \mathrm{~cm}$ de alto, tallo rizomatoso, pubescencia escasa, más densa hacia el ápice, con glándulas oleíferas conspicuas. Hojas con pecíolo de 0,5-4,5 cm largo, pubescentes, lámina de $1-11 \times 0,4-2,5 \mathrm{~cm}$, ovado angosta, ápice agudo, base aguda, margen finamente aserrado o crenado, glabras o pubescentes, con glándulas oleíferas. Flores subsésiles, agrupadas en verticilastros multifloros, de 10-20 flores, contiguos hacía el ápice, espaciados $0,3-1,5 \mathrm{~cm}$ hacia la base; reunidos en pseudoracimos terminales densos de 3-35 cm. Brácteas florales caducas o persistentes, de 4,5-12 mm, ovadas, pubescentes, no amplexicaules, color verde; cáliz de 4-7 mm, 4-5-nervado, labio superior ápice irregularmente entero o 3(4) dentado, labio inferior ápice 2-dentado, pubescente en ambas caras, con glándulas oleíferas conspicuas. Corola blanca o color azul, con mácula blanca, de 10-13 mm, tubo giboso de 4-7 $\mathrm{mm}$, pubescente, labio superior de $3-5,5 \mathrm{~mm}$, cóncavo, emarginado, labio inferior de $5-8 \mathrm{~mm}$, trilobado, el medio mayor y emarginado. Estambres inclusos. Estilo exerto, ensanchándose hacia el ápice, de $8 \mathrm{~mm}$. Clusas de 1,8-2 mm, elipsoides, trígonas, pardas, finamente granulosas.

Distribución. Salvia uliginosa es nativa del sur de Brasil, Uruguay y noreste y centro de Argentina.

Observaciones. Bentham (1833: 251) menciona tres sintipos en el protólogo de $S$. uliginosa, coleccionado por St. Hilaire, Sellow y Parker. Se elige como lectotipo el material de Sellow porque es el único sintipo del cual se encontraron ejemplares. Se cuenta con una foto del duplicado destruido de Berlin (foto F 17676!).

Se emplea como digestiva y estimulante.

\section{Material representativo examinado}

ARGEnTINA. Buenos Aires. Pdo. Quilmes, III-1913, Rodriguez 190 (SI). Corrientes. Depto. Santo Tomé, ruta 94, III-2008, Múlgura 4344 (SI). Entre Ríos. Depto. Concepción del Uruguay, 25II-1905, Hicken 4043 (SI). Misiones. Depto. Candelaria, 26-II-1999, Zuloaga 6920 (SI). Santa Fe. Depto. La Capital, $9 \mathrm{~km}$ al sur de Cagastacito, $27-$ XII-1985, Pensiero 2374 (SI). Santiago del Estero. Depto. Guasayán, Villa La Calera, 6-IV-1944, Pierotti 2 (SI). 


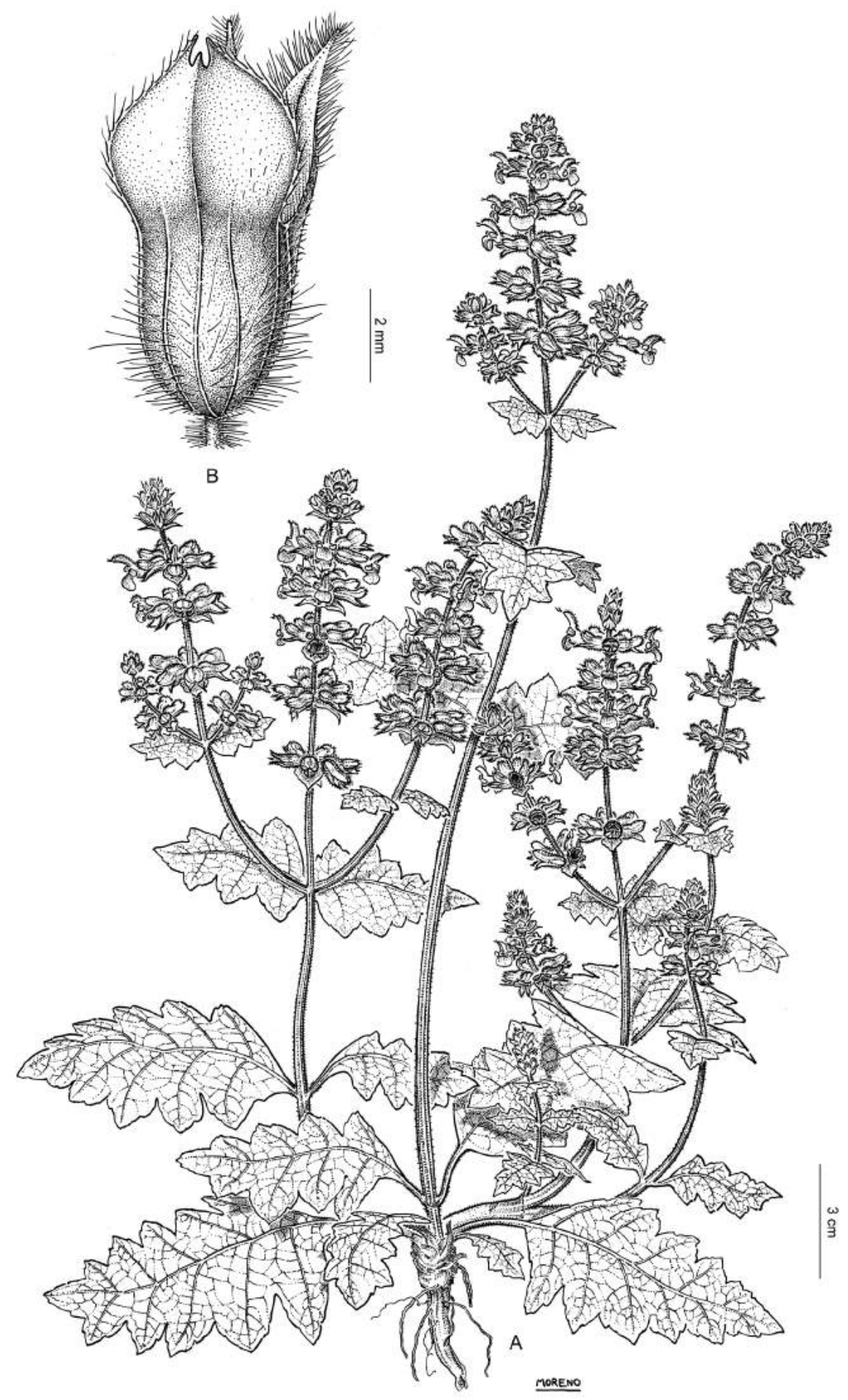

Fig. 21. Salvia verbenaca. A, aspecto general. B, flor. De Pastore 1236, SI. 
Salvia verbenaca L., Sp. Pl. 1: 25. 1753. Horminum verbenacum (L.) Mill., Gard. Dict. (ed. 8) 1: HOR. 1768. Larnastyra verbenaca (L.) Raf., Fl. Tellur. 3: 92. 1837. TIPO: "Habitat in Europae pascuis" "Horminum syl. minus inciso folio fl. azureo" en J. Barrelier, Pl. Galliam: 24, t. 208. 1714 (lectotipo designado por F. Del Carratore et al., Pl. Biosystems 132: 173, f. 3. 1998). Fig. 21.

Sufrútice, hasta de $50 \mathrm{~cm}$ de alto, tallos pubescencia híspida, principalmente sobre las aristas. Hojas con pecíolo de 5-7 cm, lámina de 2-8 × 3-5 $\mathrm{cm}$, elípticas, ápice agudo u obtuso, base aguda, textura membranácea, margen marcadamente crenado-dentado-lobulado, pubescencia estrigosa en cara abaxial, cara adaxial glabra. Flores pediceladas, pedicelo de 2-3 mm, agrupadas en verticilastros de 5-7 flores, reunidos en pseudoracimos terminales laxos o densos, de $10-20 \mathrm{~cm}$. Brácteas florales persistentes, de 4-5 mm, elípticas, híspidas, no amplexicaules, color verde; cáliz de 5-7 mm, 5-nervado, labio superior ápice 3-dentado con diente medio menor, labio inferior ápice 2-dentado, pubescencia híspida, con pelos largos en los margenes y hacia la base. Corola color violeta, lila, con mácula estriada blanca, de $8 \mathrm{~mm}$, tubo largo de 5 $\mathrm{mm}$, pubescencia escasa en la mitad superior externa, anillo oblicuo de pelos en la parte interna de la corola cerca de la base, labio superior de 5-8 $\mathrm{mm}$, cóncavo, emarginado, labio inferior de 7-9 mm, trilobado, el medio mayor y emarginado. Estambres inclusos. Estilo exerto, de $7 \mathrm{~mm}$. Clusas de 2,5 mm, ovoides, castaño oscuras, finamente granulosas.

Distribución. Salvia verbenaca es originaria de la región mediterránea de Europa y África. En Argentina es adventicia, se la encuentra desde el nivel del mar hasta los 2500 m s.m., escapada de cultivo y naturalizada ampliamente en la provincia de Buenos Aires. También crece espontáneamente en Córdoba, La Pampa, Mendoza y San Luis. También presente en Chile y Uruguay.

\section{Material representativo examinado}

ARGENTINA. Buenos Aires. Pdo. Gral. Pueyrredón, Mar del Plata, 14-I-1937, Nicora 1322 (SI). Córdoba. Depto. Calamuchita. Sierra Morena, XII-1923, Hicken s.n. (SI). La Pampa. Depto. Utracán, Gral. Acha, XI-1959, Cano 644 (BAB).
Mendoza. Depto. La Heras, Villavicencio, 4-X1987, Lagiglia 7819 (SI). San Luis. Depto. La Capital, XI-1975, Anderson 2898 (SI).

\section{TAXONES EXCLUIDOS}

En la Flora de Entre Ríos (Crespo, 1979) se trata la especie Salvia officinalis L., originaria de la región mediterránea de Europa y África con la aclaración de que es un taxón "exótico introducido". Todos los ejemplares que se encuentran en los herbarios consultados provienen de plantas cultivadas. Por lo tanto, en el presente tratamiento no se incluye este taxon por considerarlo no naturalizado en Argentina (Pyšek et al., 2004).

En este tratamiento se considera a la especie Salvia brevipes Benth. no presente en Argentina. Los materiales determinados como tal por autores previos (Crespo, 1979) corresponden a S. ovalifolia var. ovalifolia o $S$. ovalifolia var. villosa.

Briquet (1896: 863) describre Salvia amplifrons y posteriormente Epling (1935: 68) diferencia $S$. amplifrons de $S$. personata porque éste último posee hojas con pubescencia únicamente sobre las venas, mientras que en $S$. amplifrons la pubescencia es homogénea en las hojas; a su vez, el cáliz de $S$. personata es de dimensiones menores. Uno años después, Epling (1960: 148) cita S. amplifrons Briq. para Argentina, mencionando dos ejemplares, uno de Tucumán, coleccionado por Olea (UC) y otro de Salta, coleccionado por Pierotti (UC). Sin embargo, el estudio de estos ejemplares evidencia que se tratan de $S$. personata, y no se ha encontrado, hasta el momento, ningun material que se corresponda con S. amplifrons. Wood (2007), al tratar las especies de Salvia para Bolivia, no menciona la presencia de S. amplifrons en Argentina. Por lo cual, en el presente tratamiento se considera que $S$. amplifrons no crece en Argentina. Los ejemplares citados como tal para el territorio en tratamientos previos (Wood, 2007) se corresponden con S. personata.

\section{AGRADECIMIENTOS}

A los curadores de los herbarios consultados, principalmente a Mark Spencer de BM, Lesley Walshingham 
de K, Ib Friis de C, Laurence Loze de G y Andrew Doran de UC.

A CONICET por el apoyo económico brindado a través del PIP 00537/13. A los dibujantes Francisco Rojas, Marcelo Diaz y Marcelo Moreno del Instituto de Botánica Darwinion, por las excelentes ilustraciones.

\section{BIBLIOGRAFÍA}

Bentham, G. 1833. Labiatarum genera et species. Fasc. 3. London: James Ridgway and sons.

Bentham, G. 1848. Labiatae: LVII. Salvia. Pp. 262-358 en A. P. de Candolle (editor), Prodromus Systematis Naturalis Regni Vegetalis 12. Victoris Masson, Paris.

Briquet, J. 1889. Notes sur quelques Labieés Américanes. Bulletin des travaux de la Société botanique de Genève 5: 108-121.

Briquet, J. 1896. Fragmenta monographiae Labietarum. Bulletin de l'Herbier Boissier 4: 847-878.

Burkart, A. 1960. Observaciones sobre dos plantas en vías de naturalización en la Argentina. Darwiniana 12(1): 140-141.

Claßen-Bockhoff R., M. Crone \& E. Baikova. 2004. Stamen development in Salvia: homology reinvestigated. International Journal of Plant. Science 165: 475-498. DOI: http://dx.doi. org/10.1086/386565

Claßen-Bockhoff R., P. Wester \& E. Tweraser. 2003. The staminal lever arm mechanism in Salvia - a review. Plant Biology 5: 33-41. DOI: http://dx.doi.org/10.1055/s-2003-37973

Crespo, S. 1979. Labiatae, en A. Burkart (ed.), Flora Ilustrada de Entre Ríos, Colección Cientifica del Instituto Nacional de Tecnología Agropecuaria 6(5a): 294-346.

Epling, C. C. 1937. Synopsis of the Southamerican Labiatae. Repertorium specierum novarum regni vegetabilis. Beiheft. 85: 1-341.

Epling, C. C. 1939. A revision of Salvia, subgenus Calosphace. Repertorium specierum novarum regni vegetabilis. Beiheft.110: 1-383.

Epling, C. C. 1960. Supplementary notes on American Labiatae VII. Brittonia 12: 140-150. DOI: http://dx.doi. org/10.2307/2805214

Grisebach, A. 1874. Plantae Lorentzianae. Abhandlungen der Königlichen Gesellschaft der Wissenschaften zu Göttingen 19: 49-280.

Harley, R. 2008. Salvia, en F. O. Zuloaga, O. Morrone, M. J. Belgrano (eds.), C. Marticorena \& E. Marchesi (eds. asoc.), Catálogo de las plantas vasculares del Cono Sur. Monographs in Systematic Botany from the Missouri Botanical Garden 107(3): 2382-2387.

Harley, R. M.; S. Atkins, A. Budantsev, P. H. Cantino, B. Conn, R. Grayer, M. M. Harley, R. Kok, T. Krestovskaja, A. Morales, A. J. Paton, O. Ryding, \& T. Upson. 2004. Labiatae, en J.W. Kadereit (ed.), The families and genera of vascular plants Vol. 7, pp. 167-275. Berlin Heidelberg New York: Springer-Verlag.

Himmelbaur, W. \& E. Stibal. 1933. Entwicklungsrichtungen in der blutenregion der gattung Salvia L. I. Biologia generalis 8: 449-474.

Himmelbaur, W. \& E. Stibal. 1934. Entwicklungsrichtungen in der blutenregion der gattung Salvia L. II. Biologia generalis 9:129-150.

Himmelbaur, W. \& E. Stibal. 1935. Entwicklungsrichtungen in der blutenregion der gattung Salvia L. III. Biologia generalis 10:17-48.

Hunziker, A. T. 1961. Sobre la importancia de Salvia reflexa Hornem. como maleza en la provincia de Córdoba. Kurtziana 1: 304-307.

McNeill, J.; F. R. Barrie, W. R. Buck, V. Demoulin, W. Greuter, D. L. Hawksworth, P. S. Herendeen, S. Kanpp, K. Marhhold, J. Prado, W. F. Prud'homme van Reine, G. F. Smith, J. H. Wiersema \& N. J. Turland (eds.). 2012. International Code of Nomenclature for algae, fungi and plants (Melbourne Code): adopted by the Eighteenth International Botanical Congress Melbourne, Australia, July 2011. Regnum Vegetabile 154. Königstein: Koeltz Scientific Books.

O’Leary, N. \& P. Moroni. 2016. Tipificaciones en Salvia (Lamiaceae). Novon 24: 373-379. DOI: http://dx.doi. org/10.3417/2014025

Pontiroli, A. 1993. Labiatae, en A. L. Cabrera (ed.), Flora de la provincia de Jujuy. Colección Cientifica del Instituto Nacional de Tecnología Agropecuaria 13(9): 117-155.

Pyšek P., D. M. Richardson, M. Rejmánek, G. Webster, M. Williamson \& J. Kirschner. 2004. Alien plants in checklists and floras: towards better communication between taxonomists and ecologists. Taxon 53: 131-143. DOI: http://dx.doi. org/10.2307/4135498

Santos, E. Pereira dos. 1994. Contribution à la systématique du genre Salvia L. subg. Calosphace (Benth.) (Lamiaceae) : description de deux espèces nouvelles du Brésil. Bulletin du Muséum National d'Histoire Naturelle Section B, Adansonia, botanique, phytochimie 1: 155-161.

Santos, E. Pereira dos. 1995. Phylogenie et phytogeographie du genre Salvia L. section Rudes (Benth.) Epl. (Lamiacees). Biogeographica (The Hague) 71: 15-32.

Santos, E. Pereira dos. 1996. Révision de la section Rudes (Benth.) Epling du genre Salvia L., sousgenre Calosphace (Benth.) Benth. (Labiatae). Candollea 51: 19-57.

Sprengel, C. K. 1793. Das entdeckte Geheimnis der Natur im Bau und in der Befruchtung der Pflanzen. Berlin: Friedrich Vieweg dem aeltern.

Stafleu, F. A. \& R. S. Cowan. 1976. Taxonomic Literature.Vol. 1. Bohn, Scheltema \& Holkema, Utrecht.

Stafleu, F. A. \& R. S. Cowan. 1979. Taxonomic Literature. Vol. 2. The Hague (La Haya): Bohn, Scheltema \& Holkema, Utrecht, dr. W. Junk b.v., Publishers. 
Thiers, B. [continuously updated, 2014] Index Herbariorum: A global directory of public herbaria and associated staff. New York Botanical Garden's Virtual Herbarium, http://sweetgum.nybg.org/ih. (accessed 20 April 2014)

Walker, J. B. \& K. J. Sytsma. 2007. Staminal Evolution in the Genus Salvia (Lamiaceae): Molecular Phylogenetic Evidence for Multiple Origins of the Staminal Lever. Annals of Botany 100: 375-391. DOI: http://dx.doi.org/10.1093/aob/ mcl176

Walker, J. B.; K. J. Sytsma, J. Treutlein \& M. Wink. 2004. Salvia is not monophyletic: implications for the systematics, radiation, and ecological specializations of Salvia and tribe Mentheae. American Journal of Botany 91: 1115-1125. DOI: http://dx.doi.org/10.3732/ajb.91.7.1115

Wood, J. R. I. 2007. The Salvias (Lamiaceae) of Bolivia. Kew Bulletin 62: 177-222.

\section{APÉNDICE 1}

Lista de especies y taxones infraespecíficos aceptados de Salvia en Argentina.

1. Salvia atrocyanea Epling

2. Salvia calolophos Epling

3. Salvia cardiophylla Benth.

4. Salvia coccinea Buchoz ex Etl.

5. Salvia cuspidata subp. gilliesii (Benth.) J. R. I. Wood

6. Salvia exserta Griseb.

7. Salvia guaranitica A. St.-Hil. ex Benth.

8. Salvia microphylla Kunth

9. Salvia nervosa Benth.

10. Salvia ovalifolia var. nitidula (Briq.) E. P. Santos

11. Salvia ovalifolia A. St.-Hil. ex Benth. var. ovalifolia

12. Salvia ovalifolia var. villosa Benth.

13. Salvia pallida Benth.

14. Salvia personata Epling

15. Salvia procurrens Benth.

16. Salvia reflexa Hornem.

17. Salvia rosmarinoides A. St.-Hil. ex Benth.

18. Salvia rypara Briq.

19. Salvia splendens Sellow ex Nees

20. Salvia stachydifolia Benth.

21. Salvia subrotunda A. St.-Hil. ex Benth.

22. Salvia uliginosa Benth.

23. Salvia verbenaca $\mathrm{L}$.

\section{APÉNDICE 2}

Índice de colectores: Cada espécimen es citado por el nombre del primer colector y número de colección. Se indica entre paréntesis el número de orden del taxón al que se corresponde (véase Apéndice 1).

Ahumada, O. 4178 (14), 8370 (18); Anderson, D. 2898 (23); Andrada, A. s.n. LIL 610979 (4); Arbo, M. 9364 (9); Arenas, P. 243 (8), 293 (20); Argañarás, J. 141 (7), 243 (5), 749 (3); Ariza Espinar, L. 1733 (2), 2498 (3); Arriaga, M. 541 (5), 542 (5).

Báez, F. 48 (11); Barañao, J. 142 (15); Belgrano, M. 314 (11); Bertoni, M. s.n. (11), 630 (9); Bertolini, P. 11 (15); Bianco, C. 3778 (4); Biganzoli, F. 33 (11); Bissoni, D. 41 (5), 731 (23); Biurrun, F. 4507 (2); Boelcke, O. 1416 (13), 5100 (15), 6382 (7), 8722 (23); Burkart, A. 3641 (15), 4273 (13), 4569 (7), 5020 (23), 7941 (4), 8260 (22), 10421 (5), 10551 (22), 10921 (2), 11268 (20), 14671 (7), 15322 (11), 19351 (9), 21894 (12), 23471 (22), 23810 (3), 25786 (12), 26780 (7), 27067 (22), 27879 (13), 27880 (22), 29585 (3), 31072 (9); Burmeister, C. 29 (4).

Cabrera, A. 5647 (13), 6479 (3), 14097 (20), 26060 (3), 27229 (2), 28400 (10), 28288 (17), 28818 (4), 29067 (11), 29163 (22), 29265 (9), 29347 (11), 29479 (7), 30320 (14), 30436 (14), 34249 (14), 34261 (14), 34856 (14); Cano, A. 644 (23); Capurro, R. s.n. BA 55521 (7); Carette, B. 964 (5); Castellanos, A. 4066 (15), 46969 (5), s.n. BA 20167 (2), s.n. BA 20169 (5), s.n. BA 24/939 (22), s.n. BA 25/2651 (5), s.n. BA 25/497 (5), s.n. BA 27/883 (5), s.n. BA 28/335 (5), s.n. BA 30/606 (2), s.n. BA 30/608 (5), s.n. BA 31/1292 (13), Castellanos s.n. BA 31/1295 (22), s.n. BA 33907 (5), s.n. BA 36869 (5), s.n. BA 46968 (20), s.n. BA 47563 (5); Castex s.n BA 28/614 (8); Castillon, L. 1681 (20); Cialdella, A. 60 (5), 262 (2), 318 (18), 522 (2).Correa, M. 18 (15), 7982 (21). Covas, G. 18524 (2). Cozzo, D. 312 (2). Cristobal, J. 1280 (3), 1563 (13), 2286 (9). Cuezzo, A. 32 (4), 2097 (16), 4744 (19); Charpin, A. 20185 (21).

Daguerre, J. 123 (23); De la Sota, E. 199 (18), 2975 (7); Deginani, N. 155 (14), 1849 (13), 1918 (13), 2177 (5); Dematteis, M. 1336 (9); Denham, S. 116 (13); Descole, H. 3279 (11); Diem, D. 1672 (10); Diers, L. 64 (20); Dimitri, M. 326 (4), s.n. SI 203541 (4); Donadio, S. 36 (5). 
Estrada, M. s.n. BAB 22230 (13); Ezcurra, C. $529(5)$.

Fabris, H. 681 (15), 3112 (18), 5168 (1), 7833 (14); Falcone, R. 3620 (5); Fano, H. s.n. SI 19852 (16); Ferrucci, M. 6424 (9), 9364 (9); Filipovich, R. 469 (20); Flossdorf, A. 48 (5); Fortunato, R. 1315 (3), 1325 (3), 2056 (13), 2754 (3), 4409 (3), 7396 (4), 8062 (9), 8785 (3).

Gallardo, A. s.n. BA 883 (4); García, A. 28058 (8); Gareiso, A. 58 (11); Gez, J. s.n. BA 31/288 (5); Giambiagi, D. s.n. BA 879 (9); Giardelli, M. 128 (2); Guaglianone, R. 1471 (2), 1858 (1), 2937 (21).

Hauman, L. 812 (5), 823 (9), 971 (13), s.n. BA 24/2123 (11); Hicken, C. 226 (3), 289 (3), 919 bis (23), 4043 (22); Holmberg, E. 83 (15), 353 (19); Huidobro, A. 5081 (7), 5432 (7); Hunziker, J. 9965 (9), 11460 (7), 12311 (2), 12441 (2), 15898 (16), 16152 (7), 16369 (5), 18654 (13); Hurrel, J. 1591 (7), 6008 (19), 6031 (19).

Ibarrola, O. 2400 (22); Isern, J. 8151 (13); Iudica, C. 223 (20), 280 (1).

Job, M. 7086 (5), s.n. BA 29129 (15); Jörgensen, P. 437 (7), 788 (5), 1167 (20), 2235 (3), 2237 (3), 30917 (21); Juarez, B. 87 (5).

Keller, H. 3361 (7); Kermes, E. 131 (21); Kiesling, R. 1277 (18), 4823 (2), 5757 (20), 6990 (5), 7874 (2); King 251 (13); Krapovickas, A. 410 (15), 1449 (18), 1535 (18), 2408 (4), 2642 (15), 4583 (2), 11314 (13), 11689 (9), 11771 (4), 14871 (9), 15015 (10), 15127 (17), 15281 (11), 15331 (7), 15839 (3), 17160 (9), 18291 (11), 20047 (13), 21141 (9), 23966 (13), 24140 (9), 24292 (21), 26468 (21), 28661 (11), 28888 (7), 28931 (17), 29543 (4), 36043 (2), 37396 (5), 41029 (9), 46644 (2).

Lagiglia, H. 7819 (23); Lanfranchi, A. 1547 (2); Lee Anderson, D. 2898 (23); Legname, V. 8956 (2); López 94 (5); Lorentz, P. 57 (20), 111 (20), 542 (5); Lourteig, A. 2894 (10).

Maranta, A. 1066 (3); Martínez Achebanch, G. 15 (3); Martínez Crovetto, R. 2685 (15), 3392 (4), 9487 (10), 9841 (11), 11509 (11); Maruñak, V. 23 (7); Meyer, T. 415 (13), 4611 (20), 6435 (13), 6440 (13), 8975 (13), 9768 (18), 14572 (23), 21930 (14), 22184 (18); Molfino, J. 963 (3), s.n. BA 967 (17); Montes, J. 300 (11), 318 (10), 483 (10), 570 (11), 710 (11), 2499 (11), 1210 (11), 7015 (10), 15503 (11), s.n. BA 53717 (10); Monticelli, J. 4025 (2); Morrone, O. 576 (11), 749 (7), 983 (7), 1247 (7), 3487 (14), 3894 (14), 3979 (13);
Múlgura, M. 2227 (10), 2973 (11), 3352 (7), 4143 (20), 4344 (22), 4359 (17), 4369 (17); Muniez, A. s.n. BAB 65297 (11).

Negritto, M. 492 (1); Nicora, E. 210 (7), 358 (7), 468 (23), 679 (8), 737 (8), 769 (8), 1322 (23), 1327 (8), 1790 (5), 3273 (12), 7823 (13), 9959 (17); Niederlein, G. 683 (11), 975 (9), 977 (9), 978 (11), 1859 (7); Novara, L. 9600 (8), 10128 (20); Novatti, H. 51 (11).

O'Donnell, C. 2804 (14), 2946 (14).

Palacios, R. 2155 (22), 2259 (22); Partridge, W. s.n. BA 61915 (17), s.n. BA 60893 (9); Pastore, A. 321 (13), 1236 (23), s.n. BA 3174/74 (20); PaulaSouza, J. 7192 (9), 8159 (13); Pedersen, T. 26 (9), 5173 (9), 10811 (14), 12426 (13); Pensiero, J. 2374 (22), 3157 (13); Pereira, M. s.n. (14); Pérez Moreau, R. 8318 (13), 8320 (22); Perrone, V. 55132 (5), s.n. BA 54578 (7), s.n. BA 69603 (2); Pierotti, H. 2 (22); Pire, J. 7 (4); Pozner, R. 318 (5), 415 (2); Prina, A. 1646 (5); Pujals, J. 128 LIL 84413 (15).

Queiroz, L. 13354 (18). Quiroga, H. 877 (10).

Ragonese, A. 148 (14), 2073 (3), s.n BA 13351 (3); Renvoize, S. 3278 (21); Rodriguez, F. 13 (13), 32 (10), 66 (15), 156 (18), 190 (22), 238 (11), 386 (14), 387 (10), 399 (20), 434 (11), 645 (21), 808 (23), 824 (5), 825 (20), 1460 (19), 1463 (6); Romanczuk, M. 695 (21); Romero 3720 (20); Rosa 972 (16) ; Rotman, A. 71 (15), 662 (14); Ruiz, L. 211 (5).

Salgado, C. 470 (3); Sánchez, I. 788 (3); Saravia Toledo, C. 13925 (14); Schinini, A. 8102 (4), 8207 (9), 12653 (13), 13029 (9), 16738 (9), 18959 (9), 34582 (1), 34660 (14); Schreiter, R. 47 (20), 48 (20), 163 (18), 360 (14), 444 (20), 448 (5), 2809 (14); Schoreter, C. 34 (4); Schulz, O. 1140 (3), 12505 (3), 18324 (3); Schwarz, G. 565 (10), 2229 (9), 2301 (9), 4073 (7), 5086 (21), 7988 (21); Sede, S. 501 (2); Seijo, E. 1759 (2), 2551 (15); Sesmero, E. 387 (9); Slanis, A. 326 (14), 31 12-2008 (1), 56 04-2008 (18); Sleumer, H. 3544 (20), 3994 (6); Soraru, S. 6 (7); Sparre, B. s.n. LIL 334926 (15); Spegazzini, C. 264 (10), 17185 (21), s.n. BAB 17241 (3), s.n. BAB 33419 (4), s.n. BAB 28678 (7); Stienstra, B. 25289 (8); Stofella, A. 104 (3).

Toursarkissina, M. s.n. BA 67837 (13); Tedone, F. 5203 (3); Terribile 284 (4); Tracanna s.n. LIL 608048 (8); Tressens, S. 418 (10), 993 (9), 1662 (9), 1767 (9), 2022 (9), 3843 (9), 5849 (7); Troncoso, N. 1310 (8); Tur, N. 1913 (11). 
Ulibarri, E. 620 (2), 1512 (4), 1759 (5).

Vanni, R. 1517 (17), 1541 (9), 2994 (7), 4112 (9); Van de Venne, H. 350 (21), 884 (4); Varela, F. s.n. LIL 135454 (18); Venturi, S. 21 (15), 109 (7), 130 (13), 248 (15), 260 (4), 273 (13), 935 (15), 982 (18), 1522 (20), 2642 (14), 2659 (20), 3045 (20), 3764 (5), 4774 (20), 4956 (20), 7880 (5), 8119 (18), 8708 (14), 10759 (18).

Worth, A. 129 (13).

Xifreda, C. 2076 (14), 2081 (18), 2090B (5),
2095 (20), 3203 (18), 3220 (5).

Zapata, M. 21d (14); Zaravia Toledo 13357 (14); Zardini, E. 870 (7); Zotta s.n. BA 27/81 (11); Zuloaga, F. 635 (10), 892 (9), 2829 (18), 6122 (5), 6235 (14), 6916 (11), 6920 (22), 8455 (2), 8523 (14), 8615 (2), 8627 (2), 8670 (14), 9297 (5), 9329 (5), 10086 (18), 10263 (14), 10334 (20), 10336 (1), 10614 (2), 10837 (20), 11128 (5), 11796 (5), 12965 (2), 13357 (11), 13482 (20). 